\title{
SI MOHAMMED AZIZ HUBIESE SIDO GHILENO: EL ROL DEL DERECHO EN LA INCLUSIÓN FINANGIERA Y LA PROTEGGIÓN DE LOS DEUDORES HIPOTECARIOS DESDE EUROPA A CHILE
}

\author{
IRINA DOMURATH*
}

\begin{abstract}
Este artículo explora el rol que tiene el derecho en la expansión de la propiedad sobre la vivienda y la protección del sobreendeudamiento en los créditos hipotecarios. Se argumenta que la dimensión que tiene el derecho en el acceso, que tiene que ver con ampliar la inclusión financiera de los consumidores a los mercados financieros, está más desarrollada que su dimensión protectora, que consiste en proteger a estos consumidores del sobreendeudamiento. Un caso sobre el punto es el caso Aziz del Tribunal de Justicia de la Unión Europea (TJUE). Se demuestra que la inclusión financiera es un concepto falaz, si no es acompañado de medios para la protección frente a riesgos inherentes. En último término, el objetivo de la inclusión financiera y social, la democratización del crédito no se logra, y la propiedad sobre la vivienda se pone en riesgo. Si bien el énfasis del artículo se centra en el marco regulatorio europeo, se concluye con algunas reflexiones comparativas sobre el derecho chileno, para responder a la pregunta: ¿qué habría pasado si Mohammed Aziz hubiese sido chileno?
\end{abstract}

Palabras clave: Inclusión financiera, sobreendeudamiento, derecho hipotecario, derecho del consumidor, derecho europeo, derecho chileno.

\section{INTRODUGGIÓN}

En julio de 2007, Mohammed Aziz celebró un contrato de mutuo garantizado con una hipoteca otorgada por un banco español. El monto garantizado era de 138.000 euros, pagaderos en cerca de 400 cuotas por un período de más de 30 años. El señor Aziz tenía un salario mensual fijo de 1.341 euros, y las cuotas mensuales ascendían a más de la mitad de su ingreso mensual. ${ }^{1}$ El señor Aziz pagó el crédito por 10 meses, hasta que perdió su trabajo. Después de intentar infructuosamente que

\footnotetext{
* University of Amsterdam, Holanda (irina.domurath@posteo.de). Artículo recibido el 19 de abril de 2019, y aceptado para su publicación el 31 de mayo de 2019. Traducción de Alberto Pino Emhart.

1 CJEU, 14/03/2013, C-415/11 Mohamed Aziz v Caixa d'Estalvis de Catalunya, Tarragona i Manresa (Catalunyacaixa) (2013), ECLI:EU:C:2013:164; los hechos del caso pueden consultarse en los parágrafos 18 - 31, y la opinión de AG Kokott en C-415/11 (Aziz).
} 
el señor Aziz siguiera pagando, el banco persiguió el crédito judicialmente. En un remate judicial realizado en julio de 2010, ninguna oferta fue recibida. El tribunal concedió la apropiación de la propiedad al cincuenta por ciento de su valor. El señor Aziz fue desalojado de su casa y, como consecuencia de una particularidad del derecho español, siguió siendo responsable por el pago del remanente del crédito.

Este caso, que condujo a una de las decisiones más importantes del Tribunal de Justicia de la Unión Europea (TJUE) desde la crisis financiera de 2008, ilustra acerca de dos fenómenos conectados en nuestros tiempos: la propiedad de la vivienda y la inclusión financiera. Actualmente, la propiedad privada de la vivienda es probablemente una de las instituciones sociales más amplias en la vida moderna. A partir del surgimiento de los derechos humanos y políticos con la Revolución Francesa, la propiedad privada de la vivienda ha sido considerada un pilar de la libertad individual. ${ }^{2}$ Apoyado por el desarrollo del mercado financiero, que permite aumentar la inversión en bienes inmuebles, el endeudamiento privado para la adquisición de una vivienda se ha convertido en un lugar común. Al mismo tiempo, la crisis financiera de 2008 y casos como el del señor Aziz nos han recordado que el dominio privado de la vivienda no puede darse por sentado, y que más frecuentemente que no, se funda en el pago de un crédito hipotecario. Las repercusiones sociales de una "propiedad de la vivienda fallida" difícilmente pueden ser subestimadas.

Este artículo explora el rol del derecho en este desarrollo, con un énfasis en lo que ha ocurrido durante las últimas décadas. Se basa en el supuesto que el derecho afecta la expansión del crédito hipotecario. Del mismo modo, frente al escenario propuesto por la crisis financiera de 2008, se sostiene que también debe proveerse de herramientas para proteger a los deudores hipotecarios del sobreendeudamiento. Argumento que el marco normativo vigente actualmente enfatiza, el acceso al crédito hipotecario a expensas de la protección del sobreendeudamiento.

$\mathrm{El}$ argumento se despliega mediante dos pasos principales. En primer lugar, el artículo describe el desarrollo de la economía política de la propiedad de la vivienda y la expansión de los créditos hipotecarios, y explica la falacia de sus supuestos bási$\cos$ (II). Y en segundo lugar, se examina con mayor detalle el rol del derecho en este desarrollo con un foco en las reglas vigentes del derecho de la Unión Europea (III), tanto del derecho regulatorio como del derecho contractual (III.1). En este punto, veremos que, mientras el marco regulatorio del derecho europeo claramente enfatiza el ámbito de la disponibilidad para el acceso a créditos hipotecarios para los consumidores (III.2), desatiende los elementos de resguardo necesarios para proteger a los deudores hipotecarios del sobreendeudamiento (III.3). Las causas más relevantes de sobreendeudamiento -la falta de medios financieros y el advenimiento de eventos imprevistos- no son tomados en cuenta para el diseño de las principales normas sobre la supervisión de los mercados financieros, las evaluaciones de solvencia económica [creditworthiness assessments] (CWA), y el control de cláusulas abusivas. Como consecuencia, estas normas no pueden garantizar la propiedad privada sobre la vivienda.

2 Para una poderosa refutación de este supuesto, véase Mattei (2014). 
El artículo finaliza con algunos comentarios que comparan el marco regulatorio europeo con las normas chilenas más pertinentes, esbozando una imagen diferenciada de la protección de los deudores hipotecarios en Chile (IV).

\section{LA POLÍTICA EGONÓMICA DE LA PROPIEDAD SOBRE LA VIVIENDA Y LOS GRÉDITOS HIPOTEGARIOS}

\subsection{La retirada de los estados de bienestar: El caso del derecho a la vivienda}

Durante las últimas décadas, los Estados a lo largo de todo el mundo se han retirado de la provisión directa de bienestar a sus ciudadanos. El envejecimiento de la población y las tasas altas de desempleo ejercen presión sobre los sistemas públicos de salud y de pensiones, así como los presupuestos en seguridad social. Con el despliegue de ideas neoliberales, los Estados han intentado limitar los presupuestos públicos mediante recortes en la política social. Actualmente vivimos en una política económica con Estados de bienestar subdesarrollados, en los cuales los gobiernos confian cada vez más en beneficios dirigidos, grandes transferencias de la responsabilidad al sector privado y cambios en las reglas para la elegibilidad de los beneficios. ${ }^{3}$ Las políticas han ido aumentando el énfasis en la agencia individual, por ejemplo respecto al empleo y la búsqueda de trabajo, y en los requisitos para obtener beneficios por desempleo.

En la misma línea general de la escuela de pensamiento alemana-austríaca ordoliberal, el rol del Estado en este proceso de privatización reside en poner en su lugar las regulaciones institucionales y legales que liberan al mercado de distorsiones. ${ }^{4}$ En esta tradición, la escuela de Chicago aboga por minimizar las intervenciones del Estado en los mercados. ${ }^{5}$ Bajo esta postura, la intervención estatal en los mercados debiera ser reducida y las industrias que eran previamente del sector público debieran ser privatizadas y sujetas al control de las fuerzas del mercado. ${ }^{6}$ Para poder darle legitimidad al recorte de las políticas sociales, los gobiernos persuaden a sus votantes de que las pérdidas inferidas en algunos de ellos pueden aun aparecer como una proposición electoralmente atractiva. ${ }^{7}$ Para este fin, utilizan la teoría económica como una especie de soporte que les ayuda a convencer a los votantes de que el recorte en el presente los llevará a futuras recompensas. ${ }^{8}$

3 Castles et al. (2010).

4 Rose (1999).

5 Defendido de manera más relevante por FRIEDMAN (2002). La cercana conexión entre las escuelas austríacas y de Freiburg es llevada a cabo, no exclusivamente pero de manera más importante, por Friedrich HaYeK, quien trabajó no solo en Freiburg y Viena, sino también en Chicago. Luego conoció también al dictador chileno Augusto Pinochet.

6 Fulcher (2004), pp. 49-50.

7 Pierson (1996), p. 242.

8 La teoría económica clásica de la elección y la teoría del agente principal son las más utilizadas. Ambas plantean que las compañías privadas operan más eficientemente que las compañías administradas por entes públicos. PARKer (1998), pp. 30-31. En este sentido, la teoría económica es un medio poderoso para apoyar el establecimiento de las "expectativas ficticias" relativas a una narrativa de un futuro imaginado. BECKERT (2016); BECKERT (2019). 
Las finanzas son el "conductor" de los esfuerzos de privatización. ${ }^{9}$ Confiando en los mercados financieros, los gobiernos proveen de recursos financieros a beneficiarios en la cumbre de la pirámide social y luego les venden activos públicos a cambio de esos recursos, convirtiendo con ello el bienestar público en bienestar privado. ${ }^{10}$ La narrativa consiste en sostener que la acumulación de activos privados ejerce presión para buscar oportunidades de inversión, ofreciendo un alivio al presupuesto público y al mismo tiempo proveyendo de oportunidades para los dueños de los activos privados. La expansión del crédito es el factor más importante en la situación financiera de los ciudadanos. ${ }^{11}$

La propiedad de la vivienda es un problema central en este contexto. Los desarrollos del sector inmobiliario, con variaciones entre los Estados, han seguido la misma tendencia del aumento en la privatización y comodificación a lo largo del mundo. Mientras que el sector inmobiliario en Estados Unidos era ampliamente dominado por la propiedad privada de la vivienda, programas extensos de vivienda social coexistieron en paralelo de la propiedad privada de la vivienda en Europa. ${ }^{12}$ Especialmente después de la Segunda Guerra Mundial, se desarrollaron programas de vivienda pública más orientados al bienestar en muchos países de Europa. Sin embargo, durante la década de 1970, se comenzó a desplegar una tendencia convergente. Sin perjuicio de las diferencias nacionales, los Estados europeos redujeron incrementalmente su involucramiento en los sectores inmobiliarios, confiando cada vez más en desarrollos del mercado liderados por instituciones financieras. ${ }^{13}$ Para promover la propiedad privada de la vivienda, los Estados adoptaron múltiples medidas para favorecer el acceso a recursos financieros, desde subsidios al acceso más abierto para obtener créditos hipotecarios. En conjunto con subsidios a la propiedad, como deducciones de impuestos, subsidios a los intereses y tasas de intereses bajas, el acceso abierto a créditos hipotecarios permitió a los individuos tener acceso a la vivienda en mercados privatizados, no teniendo con ello que confiar en el gobierno para que les provea una vivienda (a un valor asequible).

Ahora bien, la propiedad privada de la vivienda es considerada como un objetivo de bienestar, ${ }^{14} \mathrm{y}$ un sustituto de otros mecanismos de bienestar otorgados por el Estado. ${ }^{15}$ Discutiblemente, los pensionados que son dueños de su propia vivienda necesitan niveles más bajos de pensiones proveídas por el Estado. Como consecuencia, los Estados podrían disminuir su gasto en prestaciones sociales para las personas

9 Huffschmid (2009).

10 Huffschmid (2009), pp. 49, 53-54.

11 Comparato (2018).

12 Harloe (1995), p. 211.

13 Edgar et al. (2002), p. 2; también: Logemann (2012).

14 Conley y Gifford (2006), p. 58.

15 Conley y GifFord (2006), p. 75, aunque los autores no comprueban evidencia de una decisión consciente del Estado para promover la propiedad de la vivienda sobre programas de bienestar. 
mayores. ${ }^{16}$ Más aun, la propiedad de la vivienda juega un rol fundamental en la redistribución del ingreso dentro del ciclo de vida de los individuos, ${ }^{17}$ reduciendo la laguna que existe entre los ingresos promedio de los jubilados y las rentas promedio de la población total. ${ }^{18}$ Por lo tanto, la riqueza privada es considerada como una herramienta para la protección social, en un contexto en el que la actividad estatal para mitigar la desigualdad (mediante prestaciones sociales) es escasa. ${ }^{19}$

El marco regulatorio que permite el financiamiento de los sectores inmobiliarios debe enfocarse en establecer un ambiente de mercado en el cual puede florecer la innovación financiera. Ello significa que debe permitirse la competencia para poder permitir la entrada al mercado a nuevos actores. Más aun, la desregulación es necesaria para que los actores competitivos busquen nuevos productos financieros para poder atraer consumidores. En la siguiente sección, veremos cómo la entrada al mercado de nuevas instituciones financieras y el desarrollo de nuevos vehículos financieros, como la securitización, fueron cruciales para permitir la expansión del crédito hipotecario tanto en Estados Unidos como en Europa. Al mismo tiempo, casos como el del señor Aziz muestran que la inclusión financiera y la expansión del crédito no necesariamente conducen a la satisfacción del bienestar social individual.

\subsection{La expansión falaz del crédito}

En Europa, la narrativa política estableciendo la propiedad privada de la vivienda y la expansión del crédito como objetivos de política es planteada como inclusión social a través de la inclusión financiera. ${ }^{20}$ Una vez que un consumidor es incluido financieramente en el mercado común, el consumidor puede adquirir los bienes y servicios requeridos para la inclusión social. En Estados Unidos, es la "democratización del crédito" la que describe el fuerte crecimiento en el endeudamiento de las familias de bajos ingresos, y la que justifica que deba incentivarse en tanto se cree que el aumento de los activos no solo aumenta el bienestar individual (la vivienda, los vehículos, etc.), sino que también asegura una falta de involucramiento del Estado en la satisfacción del bienestar personal. ${ }^{21}$ De manera tal que en ambos lados del Atlántico, los Estados han incentivado incrementalmente la confianza en el endeudamiento personal y el consumo para el bienestar individual. De la mano del

16 Conley \& Gifford (2006), pp. 11 y ss.

17 Kemeny (2004), p. 2; Castles (1998), p. 12 con las siguientes referencias.

18 Castles (1998), p. 16.

19 Conley y GifFord (2006), pp. 71-72.

20 Véase Comparato (2015); Comparato y Domurath (2015).

21 Olson (2003). "un resultado de los cambios en curso de los mercados financieros [incluyendo la desregulación, bajas tasas de intereses y el aumento de la competencia] ha sido la democratización del crédito. (...) Notablemente, el aumento más fuerte en la proporción de familias teniendo alguna deuda ocurrió en los dos quintiles más bajos en la distribución de ingresos", y "los beneficios que la democratización del crédito ha permitido pueden (...) apreciarse al observar el crecimiento de consumidores que se encuentran en posesión de activos no monetarios, incluyendo propiedades, automóviles y empresas". 
financiamiento de la economía - esto es, la acumulación de las utilidades por medio de canales financieros por sobre el intercambio y la producción de commodities ${ }^{-},{ }^{22}$ se espera ahora que los ciudadanos confien en productos financieros como seguros, créditos de consumo e hipotecarios, e instrumentos de inversión financiera para la provisión de su propio bienestar.

Pero es preciso establecer que la lógica de la democratización del crédito y la inclusión social y financiera puede ser falaz. La expansión del crédito no es una ruta segura para la inclusión social y prosperidad, como hemos visto en el caso de Mohammed Aziz. Mian y Sufi han descrito cómo la expansión del crédito en realidad implica una expansión a segmentos de la sociedad que previamente eran excluidos del crédito debido a un alto riesgo crediticio. ${ }^{23}$ Sin embargo, a través de la externalización del riesgo crediticio, mediante la securitización, los bancos pueden otorgar créditos a individuos con capacidades reducidas de pago, sin quedar con un riesgo de posible incumplimiento. Bajo este sistema, la expansión del crédito inherentemente conduce a la inclusión de personas con reducidas capacidades de pago a los mercados financieros. ${ }^{24}$ A pesar de que en Europa la securitización fue menos amplia, hay evidencia de estándares corrosivos para el otorgamiento de créditos, especialmente en los años previos a la crisis financiera ${ }^{25}$ La corrosión de los estándares para otorgar créditos cumple el mismo propósito que la securitización: expandir el crédito a propietarios más pobres.

El hacer responsables a los ciudadanos de su propio bienestar no solo implica que ellos deban proveerse su propio bienestar, sino también que los ciudadanos deban soportar los riesgos que conlleva este bienestar auto-proveído. Sin embargo, estos riesgos son distribuidos desigualmente en los sistemas financieros. Si bien los bancos pueden securitizar el riesgo crediticio fuera de las planillas de balances, los deudores no pueden hacerlo. Así, los bancos pueden externalizar su riesgo por medio de innovaciones financieras - como ocurrió antes de la crisis financiera a través de la securitización-, ${ }^{26}$ pero los deudores tienen que soportar el cumplimiento de sus contratos hipotecarios y, con frecuencia, son desalojados de sus viviendas. Más aun, muchos bancos han recibido en ocasiones múltiples rescates, mientras que los deudores individuales difícilmente tienen acceso a remisiones de sus créditos. ${ }^{27} \mathrm{~A}$ final de cuentas, es el deudor hipotecario, el propietario, quien debe absorber toda la pérdida de una posible caída de precios de las viviendas, mientras que el acreedor hipotecario es protegido mediante las demandas que se mantienen en contra del deudor. ${ }^{28}$

22 KRIPPNER (2005), p. 174.

23 Mian y Sufi (2014).

24 Acemoglu et al. (2015), p. 567 con las referencias allí indicadas.

25 Domurath et al. (2014).

26 Mian \& Sufi (2014), pp. 101 y ss.

27 Korczak (2009). Para un análisis comparativo entre países sobre el acceso a procedimientos concursales individuales, véase RAMSAY (2017).

28 Esta es la "dureza del crédito", Mian y Sufi (2014), p 14. 
El aumento del riesgo crediticio agregado se evidencia por el alto sobreendeudamiento de los consumidores, y el creciente aumento de las tasas de insolvencia durante las últimas décadas,${ }^{29}$ vinculado con costos de vida más altos, costos más altos de mantención de las viviendas y tasas más altas de riesgo de pobreza y exclusión social. ${ }^{30}$ Entre las principales causas del sobreendeudamiento se encuentra la falta de capacidad para el pago, como por ejemplo en créditos de proporción alta con respecto al valor y deudores de valor neto bajo y la ocurrencia de eventos imprevistos como el desempleo, que pueden interrumpir el flujo de ingresos. ${ }^{31}$ Como una consecuencia del sobreendeudamiento, tanto Estados Unidos como Europa han visto una ola sin precedentes de desalojos de deudores de sus viviendas en el período posterior a la crisis financiera. En 2016, con 2,3 billones de solicitudes de desalojos en Estados Unidos, Mark Desmond sostiene que dicho país está en presencia de una "crisis de desalojos". ${ }^{32}$ En Europa, España se vio especialmente afectada: hasta 2015, más de medio millón de personas han sido desalojadas. ${ }^{33}$ Pero a través de toda Europa, los Estados han luchado para lidiar con los deudores insolventes y para responder a la consiguiente crisis social en términos de los crecientes niveles de pobreza y falta de vivienda. ${ }^{34}$ Esto demuestra que la democratización financiera, como se denomina en Estados Unidos, o la inclusión financiera como se denomina en Europa, no conduce necesariamente a estándares de vida más altos, a un mayor bienestar, o a la inclusión social.

\section{EL ROL DEL DEREGHO: LA GONFIANZA EN LOS MERGADOS FINANGIEROS}

En esta sección, desarrollaremos cuál debiera ser el rol del derecho en estos desarrollos. Se argumenta que el derecho cumple un rol doble. En primer lugar, con respecto a la expansión del crédito y el desarrollo de la inclusión financiera, y segundo, con respecto a la protección de los deudores del sobreendeudamiento. En ambas dimensiones, el derecho actúa como una herramienta de confianza de todos los actores financieros, incluyendo propietarios y bancos, en el sistema financiero como un mecanismo tanto generador de utilidades como de bienestar privado.

Para poder aumentar la confianza en el bienestar privado, los Estados necesitan incentivar tanto las instituciones financieras como a sus ciudadanos para involucrarse en transacciones financieras. Deben incentivar a los ciudadanos para que adquieran los bienes y servicios que requieren en mercados privados para su propio bienestar a través de, entre otras cosas, los créditos. La gran mayoría de los indivi-

29 Domurath et al. (2014).

30 Para un panorama general, véase Domurath (2017), pp. 60-61.

31 Para un panorama, véase Domurath (2017), pp. 64 y ss.

32 Estos datos incluyen tanto propietarios como arrendatarios, véase www.evictionlab.org. También Desmond (2017).

33 Buck (2013); INE (2014).

34 Véanse los estudios de casos en Domurath et al. (2014). 
duos confian en los créditos hipotecarios para adquirir sus propias casas. Por lo tanto, los Estados desregulan o flexibilizan los mercados financieros, discutiblemente permitiendo la competencia e innovación, y facilitando el acceso a créditos de consumo e hipotecarios y otros productos financieros.

El principal problema detrás del incentivo a las transacciones financieras es el establecimiento de la confianza en los mercados. Actores confiados, especialmente consumidores, son necesarios para la mantención de un sistema económico capitalista. ${ }^{35}$ Como consecuencia, son necesarios los resguardos institucionales para crear y mantener la confianza entre los actores económicos, como la confianza en el repago de los créditos y confianza en la estabilidad de las divisas y mercados. ${ }^{36} \mathrm{~A}$ fin de cuentas, las crisis financieras son crisis de confianza: en 2008, cuando los primeros deudores hipotecarios comenzaron a no pagar sus créditos, sus casas fueron liquidadas como activos. La consiguiente caída en el mercado inmobiliario afectó la calidad de los instrumentos financieros respaldados por hipotecas. Los mercados comenzaron a dudar sobre los valores de los instrumentos y la solvencia de las instituciones emisoras. ${ }^{37}$

\subsection{La regulación del mercado y el derecho de los contratos}

Desde un punto de vista jurídico, los resguardos institucionales para la creación de la confianza son parte de la (macro) regulación del mercado y la (micro) regulación del derecho contractual. Tanto el derecho de los contratos como la regulación son necesarios para crear y sostener la confianza en los mercados. ${ }^{38}$ En el ámbito de los créditos hipotecarios, esto significa que los gobiernos conducen a un marco legal para los mercados financieros que enfatiza la confianza, estabilidad y fuerte protección de los derechos de propiedad. De esta manera, los Estados pueden emplear su poder regulatorio para crear una demanda por créditos hipotecarios para los bancos comerciales. ${ }^{39}$ De acuerdo a la narrativa económica, la confianza en la estabilidad de los mercados financieros y el pago de los créditos incentivan la toma de riesgos necesaria para la expansión del crédito.

La importancia de la confianza en la macro-estructura de los mercados financieros se evidencia por las respuestas regulatorias posteriores a la crisis financiera. Por ejemplo, una respuesta regulatoria de los bancos centrales frente a la falta de confianza de los inversionistas en los mercados -como ocurre siempre en las crisis financieras- es la inyección de liquidez de corto plazo en los mercados financieros. También son necesarios los rescates a los bancos para prevenir la insolvencia de la institución financiera y para preservar la confianza en los bancos centrales como prestamistas

\footnotetext{
35 Crouch (2009).

36 Beckert (2013), pp. 331 y ss.; Beckert (2016).

37 Hellwig (2009), p. 133.

38 Beckert (2013); Beckert (2016).

39 Trumbull (2012a); Trumbull (2012b).
} 
de último recurso. En la Unión Europea, como respuesta frente a la crisis, el Banco Central Europeo (BCE) ajustó sus tasas de interés para poder mantener la confianza en la estabilidad de los precios, intentó restaurar la confianza interbancaria cambiando sus políticas sobre el otorgamiento de créditos, y compró bonos. ${ }^{40}$ Todo ello sirvió para mantener la confianza en la estabilidad del sistema financiero, e incluso llevó al establecimiento de una Unión Bancaria bajo la supervisión del BCE. ${ }^{41}$

El derecho de los contratos también juega un rol fundamental en relación al acceso a los mercados financieros, incluyendo el mercado de los créditos de consumo e hipotecarios, porque establece una estructura institucional que lleva a que los acreedores crean que el capital e interés adeudados por el crédito serán pagados. ${ }^{42}$ De esta forma, todo el derecho contractual parte del principio pacta sunt servanda. Los contratos solo se celebran si el acreedor puede confiar en el cumplimiento del contrato, o en caso de incumplimiento por parte del deudor, en que podrá ejecutar el contrato. Este principio es de suma importancia en los contratos de larga duración: mientras más largo sea el período del contrato, habrá mayor inseguridad en relación al cumplimiento del contrato para el acreedor. Para poder mitigar esta inseguridad, la propiedad puede convertirse en una garantía para el caso de incumplimiento. La perspectiva de castigo sobre los deudores incumplidores a través de la ejecución del derecho real de hipoteca debiera disciplinar a los deudores para que cumplan. Esto le otorga al derecho contractual un rol fundamental en la expansión del crédito.

$\mathrm{Al}$ mismo tiempo, reconociendo la necesidad de mecanismos que protejan a los consumidores frente a los riesgos que implica la inclusión financiera si la propiedad privada de la vivienda va a llevarse a cabo, las normas jurídicas deben tender a la protección de los deudores. Utilizando el lenguaje de la Unión Europea, podemos sostener que la inclusión social a través de la inclusión financiera es una paradoja, y que la inclusión financiera debe incluir necesariamente la protección social. ${ }^{43}$ Por consiguiente, examinaremos ahora las principales normas para la expansión de los mercados del crédito y la protección de los deudores. Ambos roles del derecho serán analizados en las siguientes dos secciones, antes de trazar algunas posibles implicancias para el contexto chileno.

\subsection{El acceso a los mercados: La expansión del crédito hipotecario}

En esta sección, revisaremos con más detalle las normas adoptadas por los Estados para expandir el acceso a los créditos hipotecarios. Estas normas pueden clasificarse en perspectivas regulatorias que tienen que ver con el marco jurídico

40 Para un panorama, STARK (2009).

41 La supervisión única, resolución de los bancos, y garantías de depósito son consideradas fundamentales para la estabilidad financiera y la confianza en los mercados financieros de la Unión Europea. Para una visión general sobre los pilares la Unión de Bancos de la Unión Europea, véase https://www.ebf.eu/priorities/banking-supervision/banking-union/.

42 Beckert (2016), p. 129.

43 También Micklitz (2010). 
para la operación de los mercados financieros y perspectivas contractuales que tienen que ver con la relación entre acreedores y deudores. Con respecto a la perspectiva regulatoria, describiremos primero los desarrollos más generales, para luego revisar con más detalle el marco regulatorio de la Unión Europea relativo a la protección del consumidor en mercados financieros. El énfasis será puesto no en la supervisión prudencial regulatoria que debiera asegurar la estabilidad del sistema financiero en general, sino en las normas relativas al riesgo crediticio individual de los deudores.

\subsubsection{La regulación de los mercados financieros}

Estados Unidos fue discutiblemente el primer país en darle un empuje al financiamiento de su mercado inmobiliario. En respuesta a la Gran Depresión y su declive por largas décadas como una potencia económica global, Estados Unidos buscó recobrar su potencia económica. Necesitaba generar ingresos con los cuales financiar su déficit comercial, ${ }^{44}$ y establecer una demanda por deuda establecida en dólares americanos altamente valorizados. ${ }^{45}$ Se decidió que las industrias nacionales inmobiliarias y crediticias, y la compra de hipotecas a través de instituciones extranjeras cumplirían un rol fundamental en este ámbito. ${ }^{46}$ De esta manera, para poder incentivar los préstamos hipotecarios y expandir los mercados de los créditos hipotecarios, la Housing Act de 1934 y la creación de la Federal Housing Administration le otorgaron cobertura de seguros a los acreedores privados por la pérdida en créditos para la rehabilitación de viviendas e hipotecas para nuevas casas; simultáneamente, se establecieron subsidios para la construcción de viviendas y políticas de planificación urbana que incentivaban la expansión de las actividades de las empresas inmobiliarias y constructoras. ${ }^{47}$ La Federal National Mortgage Association (Freddie Mae), la Federal Home Loan Mortgage Corporation (Freddie Mac), y la Government National Mortgage Association (Ginnie Mae) introdujeron el crédito hipotecario estandarizado. ${ }^{48}$ Ellas trajeron hipotecas, las envolvieron y vendieron títulos de créditos respaldados por hipotecas en el mercado abierto, proveyendo de garantías para el pago prometido en los títulos crediticios. ${ }^{49}$ La securitización fue, de hecho, una de las innovaciones claves detrás de la integración del mercado financiero global, ${ }^{50}$ porque desconectó los mercados hipotecarios globalizados de los mercados inmobiliarios locales y sus vulnerabilidades a riesgos locales. ${ }^{51}$ Bajo este sistema, el énfasis no radica en la utilidad de otorgar un crédito a un consumidor individual, sino en la utilidad de la circulación global de un conjunto de hipotecas.

\footnotetext{
44 Schwartz (2012), p. 60

45 Mian y Sufi (2014), p. 97

46 Schwartz (2012), pp. 54 y ss.

47 Gotham (2012), pp. 32-35.

48 Aalbers (2012), p. 10

49 Hellwig (2009), p. 146.

50 Fligstein y Habinek (2014), p. 641.

51 Mian y Sufi (2014), pp. 95-96.
} 
En la Unión Europea, a pesar de que muchos Estados miembros ya habían participado en el impulso del financiamiento de la vivienda, la expansión de los créditos se convirtió en una parte integral del establecimiento de un mercado interno durante la década de 1990. En este ámbito, el mercado hipotecario subprime era discutiblemente mucho más pequeño y de seguro más diverso que el estadounidense. Sin embargo, los créditos hipotecarios fueron acompañados de bajas tasas de interés, el aumento de los precios inmobiliarios y un aumento de la liberalización e integración de los mercados financieros de la Unión Europea.$^{52}$ La puntuación automatizada a través de oficinas crediticias y la movida a sistemas de precios basados en el riesgo también contribuyeron a una expansión del crédito. A nivel de la Unión Europea, la Directiva de Créditos al Consumo 2008/48/EC (DCG), ${ }^{53}$ adoptada justo antes de la crisis financiera, y la Directiva sobre Créditos Hipotecarios 2014/17/EU (DCH) ${ }^{54}$ adoptada tras largas negociaciones siete años después de la crisis financiera, buscaban crear un mercado interno trasfronterizo a través de la facilitar la disponibilidad de créditos de consumo e hipotecarios. ${ }^{55}$ La Comisión Europea reconoce que la integración de los mercados hipotecarios de la Unión Europea es esencialmente dirigido por la oferta, poniendo énfasis en la libertad para el establecimiento de proveedores hipotecarios en otros Estados miembros. ${ }^{56}$

\subsubsection{Derecho europeo del consumidor: El acceso a los mercados para con- sumidores confiados}

Más allá de la expansión (macro) regulatoria de los mercados hipotecarios, la Unión Europea también establece reglas relativas a (la dimensión micro de) los contratos crediticios. La legislación europea sobre hipoteca pertenece al ámbito del derecho de consumo. La legislación de consumo se basa ampliamente en los artículos 4(2) letra a) y el artículo 114 del Tratado sobre el Funcionamiento de la Unión Europea (TFUE) ${ }^{57}$ que tiene que ver con el establecimiento y funcionamiento del mercado interno. Y desde el caso de Tobacco Advertisement, en el cual la GJEU rechazó una propuesta de directiva sobre la publicidad de productos del tabaco debido a que la principal preocupación por la salud pública no podría basarse en el artículo 114 TFUE, es claro que cualquier legislación basada en este artículo debe tener un objetivo genuino de mejorar las condiciones del mercado interno; la protección del consumidor solo puede ser un efecto secundario de dicha legislación. ${ }^{58}$ Por consiguiente, la Unión Europea actúa cuandoquiera que

52 European Commission (2005), punto 5.

53 Directiva 2008/48/EC de 2008.

54 Directiva 2014/17/EU de 2014. La fecha para que los Estados miembros incorporaran la MCD en sus sistemas internos era el 21 de marzo de 2016. A estas alturas, todos los Estados miembros han implementado la directiva, véase Anderson y Arroyo Amayuelas (2018).

55 Preámbulo 4 CCD, Preámbulo 2 MCD.

56 European Commission (2007), punto 3.

57 Treaty on the Functioning of the European Union of 2009, OJ G 326/47, 26.10.2012.

58 CJEU, 05/10/2000, C-376/98 Federal Republic of Germany v European Parliament and Council of the European Union (2000), ECLI:EU:C:2000:54. 
haya un peligro de obstrucción del mercado interno y movimientos trasfronterizos de bienes, servicios, personas y capitales.

El derecho del consumidor en la Unión Europea es dominado por estas consideraciones. Para poder establecer un mercado interno que funcione, la Unión Europea necesita consumidores confiados. De esta manera, el estándar normativo para la protección del consumidor en el derecho europeo es el consumidor "razonablemente circunspecto". Desde el famoso caso Mars, ${ }^{59}$ se supone que los consumidores en la Unión Europea sean autónomos, autosuficientes y bien informados cuando compran bienes y productos en los mercados internos. Son considerados y se supone que son actores racionales. Solo entonces podrían beneficiarse de las normas de protección de la Unión Europea. ${ }^{60}$ Por lo tanto, el marco jurídico del derecho del consumidor se orienta hacia proteger aquellos consumidores razonablemente circunspectos - este consumidor es el punto de referencia para la evaluación de los negocios con consumidores, como las prácticas comerciales y los contratos tipo-.

Para poder asegurarse que los consumidores puedan ser razonablemente circunspectos y bien informados, el derecho de la Unión Europea impone obligaciones de informar sobre los profesionales y permiten el control de las cláusulas abusivas de los contratos. El supuesto aquí es que los consumidores son las partes estructuralmente más débiles en las relaciones contractuales con profesionales. La CJEU ha dejado claro en numerosas ocasiones que la posición débil de los consumidores se deriva tanto de su poder de negociación como de su nivel de conocimiento. ${ }^{61}$ Por consiguiente, las limitaciones a la libertad contractual tanto de la parte profesional "más fuerte" como de la del consumidor como parte "débil" son consideradas justificadas. ${ }^{62}$ En el ámbito de la protección financiera del consumidor, las normas de la Unión Europea interfieren con la libertad contractual por vía del requerimiento de revisar las capacidades de pago del deudor (las evaluaciones de solvencia económica [creditworthiness assessments], CWA), y a través de los requerimientos de información y el control de cláusulas abusivas.

\section{i. Las evaluaciones de solvencia económica (ES)}

La herramienta principal del acreedor para decidir si aceptar o no un crédito con un posible deudor es la evaluación de capacidad financiera. De hecho, los CWA han sido por mucho tiempo una parte integral de las operaciones bancarias. La

59 CJEU, 06/07/1995, C-470/93 Verein gegen Unwesen in Handel und Gewerbe Köln eVv Mars GmbH (1995), ECLI:EU:C:1995:224, párrafo 24.

60 Esto hace que el consumidor "razonablemente circunspecto" sea el estándar normativo del derecho de consumo de la Unión Europea. Para una discusión diferenciada, véase Wilhelmsson (2004), Incardona y Poncibó (2007), Domurath (2013); Mak (2013).

61 Por ejemplo en el caso CJEU, 09/11/2010, C-137/08 VB Pezügï Lizing Zrt v Ferenc Schneider (2010), ECLI:EU:C:2010:659, párrafos 27 y 46; CJEU 26/04/2012, G-472/10 Nemzeti Fogyasztóvédelmi Hatóság v Invitel Távközesi Zrt (Invitel) (2012), ECLI:EU:C:2012:242, párrafo 33.

62 Hondius (2004), p. 246. 
MCD le dedica un capítulo a las CWA. El artículo 18(1) del MCD establece que el acreedor estará obligado a realizar un "exhaustivo" CWA, tomando adecuadamente en cuenta los factores relevantes "para verificar que el futuro consumidor pueda cumplir sus obligaciones bajo el acuerdo del crédito". El CWA debiera enfocarse en la capacidad del consumidor para cumplir sus obligaciones (Preámbulo 55 y artículo 18(1) MCD). Dado que el CWA se realiza con frecuencia bajo la consulta de oficinas de créditos, que recopilan y resguardan datos relativos a las obligaciones comerciales y responsabilidades de los consumidores, el artículo 20 hace que sea obligatorio el acceso no-discriminatorio a las bases de datos de las oficinas de crédito y al monitoreo del cumplimiento de los consumidores con las obligaciones a lo largo de la vida del contrato. Finalmente, el artículo 18(5) letra (a) de la MCD estipula que el crédito solo deberá estar disponible para el consumidor si el CWA indica que el consumidor será capaz de cumplir sus obligaciones financieras asumidas con la contratación del crédito. Dado que la CGD no contiene una disposición como esta, podemos asumir que la inclusión de estas disposiciones en la MCD fue influenciada por la prevalencia de prácticas sobre optimistas antes de la crisis financiera.

Los acreedores por largo tiempo han desarrollado una expertise en el análisis y monitoreo de los deudores. Por lo tanto, se considera que debieran suprimir algunos de los déficits cognitivos de los acreedores ${ }^{63}$ Ellos recopilan información histórica de los pagos y de las cuentas de los consumidores, organizan y administran la información acerca del desempeño de los deudores, y le proveen a la industria crediticia de informes previos a la celebración del contrato de mutuo. ${ }^{64}$ De manera tal que las CWA le permiten a los acreedores tener una visión más completa de la exposición total a la deuda de un individuo. ${ }^{65}$ Adicionalmente, las oficinas de crédito que son frecuentemente utilizadas por los acreedores para realizar sus evaluaciones de solvencia contribuyen a reducir la selección adversa y a detectar los deudores que están sobre comprometidos. ${ }^{66}$ La teoría económica las considera como designadas para eliminar las asimetrías de información que supuestamente existen con respecto tanto a la capacidad y voluntad de pagar el crédito por parte de los deudores. ${ }^{67}$ Cuando se realizan diligentemente, los consumidores que se encuentran más debajo de un cierto umbral en términos de ingresos y riqueza, con capacidad insuficiente para poder pagar el crédito, no obtendrán el crédito.

Si bien es evidente que el objetivo de cualquier CWA es asegurarse que el crédito será pagado, lo cual constituye el interés primario del acreedor (minimización del riesgo), resulta discutible plantearse si las CWA persiguen algún otro objetivo. En el caso Crédit Lyonnais, la GJEU interpretó el propósito de la evaluación de solvencia como el prevenir a los consumidores del riesgo de sobreendeudamiento e insolvencia,

63 Atamer (2011), p. 199.

64 Ferretti (2010), p. 1.

65 Vandone (2009), p. 77.

66 Rona-Tas (2015).

67 Por ejemplo: Jappeldi y Pagano (2002). 
y de protegerlos de contratar créditos que superen sus capacidades financieras. ${ }^{68} \mathrm{El}$ preámbulo 3 de la MCD señala que la prevención del sobreendeudamiento de la vivienda forma parte del marco regulatorio de la Unión Europea en el ámbito de los créditos hipotecarios. También las referencias en el Preámbulo 55 y el artículo 18(3) de la MCD al valor de la propiedad garantizada pueden ser interpretadas como sosteniendo que las CWA también protegen al consumidor de la pérdida de la propiedad adquirida con el crédito. Sin embargo, podemos dudar de que esto sea un objetivo por sí mismo. El Preámbulo 3 de la MCD considera la prevención del sobreendeudamiento meramente como una herramienta para restaurar la confianza de los consumidores después de la crisis financiera. La narrativa consiste en sostener que las prácticas irresponsables de otorgamiento de créditos han socavado las bases del sistema financiero así como de la confianza de los consumidores y que, por consiguiente, la Unión Europea debe intentar prevenir el sobreendeudamiento de la vivienda. Por lo tanto, la prevención del sobreendeudamiento es instrumental para el cumplimiento de un objetivo mayor: restaurar la confianza de los consumidores en el mercado interno. A través de mejores evaluaciones de solvencia, los consumidores tendrán más confianza en el mercado interno y celebrarán más transacciones transfronterizas, según este raciocinio.

\section{ii. Las obligaciones de informar}

Luego de la decisión de otorgarle un crédito a un futuro deudor, el banco le ofrecerá al consumidor un contrato estandarizado de crédito hipotecario. La MCD contiene un largo catálogo de disposiciones relativas al suministro de información para la conclusión de un contrato de mutuo. Aquí, la MCD sigue la perspectiva general del derecho de la Unión Europea de protección del consumidor, que se basa en apoyar el mercado interno y asegurar la transparencia de las transacciones económicas.

Las transacciones comerciales deben ser transparentes para poder permitir la desregulación del mercado interno porque la liberalización del mercado a través de la competencia se asume que asigna los factores de producción de una manera óptima. ${ }^{69}$ Por consiguiente, la Unión Europea debe asegurar el libre flujo y transparencia de la información, una perspectiva sostenida firmemente desde el caso central Cassis, decisión en la cual la CJEU estableció que la "mayor transparencia de las transacciones comerciales" podría lograrse proveyendo de información adecuada al consumidor. $^{70}$ Con la ayuda de la información proporcionada, el consumidor confiado puede tomar una decisión informada acerca de si quiere comprar o no el producto en cuestión. Por lo tanto, toda la legislación de la Unión Europea de derecho del consumo incluye una gran cantidad de requerimientos de información para el profesional,

68 GJEU 27/03/2014, G-565/12 LCL Le Crédit Lyonnais SA v Fesih Kalhan (2014), ECLI:EU:C:2014:190, párrafos 42 - 43. Por lo tanto, se ha sostenido que el objetivo del préstamo responsable ahora también incluye la estabilidad financiera del consumidor; véase RотT (2014), p. v.

69 European Commission (1993), puntos 2 y 5.

70 CJEU 20/02/1979, C-120/78 Rewe Zentral v Bundesmonopolverwaltung für Branntwein (1979), ECLI:EU:C:1983:202 (Cassis de Dijon). 
dado que se asume que los proveedores saben más que los consumidores acerca de los productos y servicios que ofrecen.

La MCD contiene muchos artículos que imponen requerimientos de información. El artículo 11 de la MCD tiene que ver con la publicidad como el primer contacto entre el acreedor hipotecario y deudor. Los proveedores de créditos hipotecarios deben suministrar información acerca de las tasas del crédito, el monto total del crédito, el porcentaje anual de interés, la duración del contrato crediticio, el total a pagar por el consumidor y el monto y número de cuotas. Más aun, el artículo 14 de la MCD exige la provisión de información personalizada sin demoras injustificadas y en un tiempo prudente antes que el consumidor se vincule contractualmente. Incluso después que se ha suscrito el contrato, el artículo 27 de la MCD obliga al acreedor a informar al consumidor acerca de cualquier cambio de la tasa de interés antes que dicho cambio entre en vigencia. Dado que la MCD fue adoptada siete años después de la crisis financiera, exige en parte más allá de lo requerido por la CCD que fue adoptada el 2008. Por ejemplo, la información que debe suministrarse incluye información adicional acerca de los créditos hipotecarios en monedas extranjeras, requiriendo el cálculo de una pérdida de un 20 por ciento del valor de la moneda nacional del deudor en relación a la moneda en que se acuerda el crédito. ${ }^{71}$

Además del requisito de proveer información específica acerca del contrato de mutuo, el marco legal de la Unión Europea también aborda el problema de la transparencia de la información. El artículo 14(3) de la MCD introduce el requisito de proveer información pre-contractual en una forma estandarizada, esto es, la Ficha Europea de Información Normalizada (FEIN). La estandarización se establece para permitir a los consumidores comparar diferentes ofertas de manera más fácil. La MCD impone no solo obligaciones de informar al acreedor, sino también la obligación de emplear un lenguaje accesible al proveer dicha información al consumidor. Por ejemplo, se exige que el acreedor otorgue "explicaciones adecuadas" al consumidor sobre el contrato de crédito propuesto (artículo 16 de la MCD). Por lo tanto, la FEIN contiene lenguaje más simple ("Esto significa..."; dirigirse al consumidor directamente en la forma de "usted") que los términos legales de las Directivas, reconociendo las dificultades que enfrentan los consumidores entendiendo el lenguaje financiero y jurídico. ${ }^{72}$

Combinando los deberes de informar con requerimientos de inteligibilidad, el marco legal también aborda las dificultades que pueden tener los consumidores para comprender la información proporcionada. Este es un problema especialmente grave en el caso de los servicios financieros. ${ }^{73}$ Sobre la incapacidad para evaluar las consecuencias del sobreendeudamiento, la MCD impone obligaciones tanto para el acreedor como para el deudor; con el objeto de alcanzar prácticas de préstamos y endeudamientos responsables, la MCD establece algunas advertencias a los consumidores.

71 Véase Punto 3(3) y (4) ESIS, y la posibilidad de tasas de interés variables, Punto 6(3) ESIS.

72 Véase Preámbulo 41 MCD.

73 Véase por ejemplo: Atamer (2011); Cartwright (2012); ECGG Plenary (2013), p. 14. 
Aquí, la MCD impone la obligación para el acreedor de advertir al deudor sobre posibles consecuencias por el incumplimiento con el compromiso financiero bajo el contrato crediticio (artículo 13 (1) letra n). Debido al carácter mínimo de armonización de la MCD, los Estados miembros pueden introducir mayores deberes de advertencia. ${ }^{74}$

Todas estas disposiciones se orientan claramente a establecer un equilibrio entre una información completa y comprensible que debe ser proporcionada al consumidor para que este tenga acceso al mercado hipotecario europeo interno.

\section{iii.. El control de cláusulas abusivas de los contratos}

La entrega de todo tipo de información al consumidor, independiente de la accesibilidad que tenga para el consumidor promedio razonablemente prudente, solo puede ser una parte del marco regulatorio de las hipotecas. Desde el punto de vista del favorecimiento del mercado interno, debe tomarse en cuenta que el consumidor no siempre puede utilizar la información de un modo tal que aumente la competencia. Como consecuencia de un monopolio del profesional o porque todos los competidores emplean las mismas cláusulas, los consumidores que requieren bienes y servicios no están en una posición para ir de un lado a otro buscando diferentes términos contractuales o de mejor calidad. Por lo tanto, el poder de negociación de los consumidores se inhibe usualmente debido al uso de contratos estandarizados que son presentados a los consumidores sobre una base de "tómelo o déjelo". Esto priva a la parte más débil de su libertad contractual. ${ }^{75}$

Este problema es abordado en el derecho de la Unión Europea por la Directiva 93/13/CEE sobre las cláusulas abusivas en los contratos celebrados con consumidores (DCAC).$^{76} \mathrm{Su}$ objetivo anunciado es facilitar el establecimiento de un mercado interno a través de la abolición de las cláusulas abusivas en los contratos de adhesión que impiden al consumidor poder comparar la contratación de bienes y servicios en Estados miembros distintos con reglas contractuales diferentes (Preámbulo 4-6 UCTD). Se orienta a permitir que los consumidores confien en que los contratos que celebran dentro de la Unión Europea no contienen cláusulas abusivas, que no pueden entender por el lenguaje o que no pueden identificar debido a la falta de conocimiento de los diversos sistemas jurídicos nacionales.

El artículo 3 (1) UCTD establece el criterio de la abusividad de la cláusula: "Las cláusulas contractuales que no se hayan negociado individualmente se considerarán abusivas si, pese a las exigencias de la buena fe, causan en detrimento del consumidor un desequilibrio importante entre los derechos y obligaciones de las partes que se derivan del contrato".

El Anexo a de la Directiva contiene una lista no-exhaustiva de cláusulas que son consideradas prima facie abusivas. El artículo 4 establece un método para determinar si una cláusula es abusiva:

74 Véase Preámbulo 43 MCD.

75 KeSSLER (1943).

76 Directiva 93/13/CEE del Consejo, de 1993. 
1. Sin perjuicio del artículo 7, el carácter abusivo de una cláusula contractual se apreciará teniendo en cuenta la naturaleza de los bienes o servicios que sean objeto del contrato y considerando, en el momento de la celebración del mismo, todas las circunstancias que concurran en su celebración, así como todas las demás cláusulas del contrato, o de otro contrato del que dependa.

2. La apreciación del carácter abusivo de las cláusulas no se referirá a la definición del objeto principal del contrato ni a la adecuación entre precio y retribución, por una parte, ni a los servicios o bienes que hayan de proporcionarse como contrapartida, por otra, siempre que dichas cláusulas se redacten de manera clara y comprensible.

Si bien la determinación de si una cláusula es abusiva o no en los casos específicos se deja para los tribunales nacionales,${ }^{77}$ derivado del principio de la autonomía procesal de los Estados miembros, constituye una jurisprudencia asentada de la CJEU que los tribunales nacionales deben evaluar de oficio el carácter abusivo de las cláusulas contractuales. ${ }^{78}$ Una vez que una cláusula es declarada como abusiva, los Estados miembros deben preocuparse de que sus marcos regulatorios aseguren que la cláusula no sea vinculante para el consumidor, y que el contrato "siga siendo obligatorio para las partes en los mismos términos, si este puede subsistir sin las cláusulas abusivas" (artículo 6 (1) UCTD). El artículo 7 (1) UCTD establece la obligación para los Estados miembros de asegurar la existencia de medios adecuados y efectivos para prevenir el uso continuado de cláusulas abusivas en los contratos de consumo.

La directiva UCTD ha sido en gran medida el foco de la jurisprudencia de la GJEU durante las últimas décadas. Como veremos con más detalle en la próxima sección, la GJEU ha empleado la UCTD para poder conectar la ejecución con procedimientos declarativos. Por ahora, solo debemos tener en cuenta que la UCTD es considerada clave para el establecimiento de un mercado interno. Ella busca facilitar el acceso al mercado interno para consumidores porque con su objetivo de eliminar las cláusulas abusivas buscan liberar a los consumidores de tener que navegar a lo largo de un sistema jurídico desconocido en otro Estado miembro.

\subsection{La protección de los deudores frente al incumplimiento}

Revisaremos ahora en qué medida las herramientas analizadas anteriormente para la expansión de los mercados toman en cuenta o son complementadas con mecanismos protectores que pueden ayudar a prevenir las dos principales causas de los

77 Sin embargo, la GJEU ha otorgado directrices sustantivas respecto a qué tipo de cláusulas serían consideradas como abusivas. Una parte de esta jurisprudencia es mencionada más abajo.

78 CJEU 27/06/2000, en los casos acumulados Océano Grupo Editorial SA v Roció Murciano Quintero (C-240/98) y Salvat Editores SA v Fosé M. Sánchez Alcón Prades (C-241/98), Fosé Luis Copano Badillo (C-242/98), Mohammed Berroane (C-243/98) y Emilio Viñas Feliú (C-244/98) (2000), párrafo 26; también en CJEU 03/06/2009, C-243/08 Pannon GSM Zrt v Erz'ebet Sustikn'e Gy'orfi, (2009), ECLI:EU:C:2009:350, párrafo 24; CJEU 21/11/2002, G-473/00 Cofidis SA v Fean-Luois Fredout (2002), ECLI:EU:C:2002:705. 
incumplimientos: la falta de medios financieros (créditos de proporción alta con respecto al valor y deudores de valor neto bajo) y la ocurrencia de eventos imprevistos que afectan directamente las capacidades financieras del deudor.

\subsubsection{El rol del Banco Central Europeo}

La prevención del sobreendeudamiento de los consumidores es un campo del derecho que cruza a lo largo de todas las aproximaciones regulatorias y del derecho privado. Además de una falta de medios iniciales, la capacidad de pago de los consumidores se ve por la situación macroeconómica general, dado que los impactos macroeconómicos pueden conducir, por ejemplo, al desempleo o a un alza en las tasas de interés. La estabilidad de los sistemas financieros en general también se ve afectada por las prácticas de préstamos irresponsables. Si el sobreendeudamiento es un asunto de real preocupación para los legisladores, entonces debe ser abordado a través tanto de la regulación como el derecho contractual.

Sin embargo, la supervisión regulatoria de la Unión Europea no está preocupada de la protección de los deudores. Sin perjuicio de la actividad regulatoria significativa en el ámbito de la supervisión de mercados financieros, la supervisión regulatoria se preocupa del monitoreo de riesgos sistémicos. Como tal, se dirige a la prevención de mayores impactos macroeconómicos, que pueden impactar negativamente a las capacidades de pago del deudor. No tiene relación directa con los riesgos individuales del crédito.

Hay un problema importante de ámbito y competencia. La Unión Bancaria, la última parte del puzle para la configuración del mercado interno, y una unión fiscal fueron establecidas después de la crisis financiera de 2008. Ellas complementan el mercado interno del capital y la moneda única. Sus principales elementos son la creación de un Mecanismo de Supervisión Único (SSM), bajo la prudente supervisión del Banco Central Europeo (ECB), y un Mecanismo Único de Resolución de Conflictos (SRM). Ambos se basan en el "single rulebook", un conjunto de reglas que establecen estándares para regular, supervisar y administrar el sector financiero en la Unión Europea. Dentro de su mandato de supervisión, el Banco Central reitera rutinariamente que la protección de los consumidores no forma parte de su mandato, y se remite al rol de las agencias supervisoras nacionales a este respecto. ${ }^{79-80} \mathrm{El} \mathrm{Banco}$ Central concibe su rol como limitado a la cooperación con las autoridades nacionales sobre asuntos como la protección del consumidor. ${ }^{81}$

La falta de preocupación por la protección del deudor no se mitiga con la dictación de la guía del Banco Central Europeo sobre el incumplimiento de préstamos (NPL Guidance). Esta guía establece un marco básico para dirigir la evaluación supervisora de los bancos con respecto a la administración de los incumplimientos. Por

79 Véase Preámbulo 28 de la SSM Regulation.

80 Council Regulation 24/2013 de 2013.

81 Véase Preámbulo 29 SSM Regulation. 
consiguiente, la NPL Guidance también incluye principios sobre las evaluaciones de capacidad económica. Por ejemplo, los ingresos futuros prospectivos asumidos deben ser "creíbles y conservadores", y deben tomar en cuenta el ingreso regular, gastos, bienes y deudas, gastos de vida, perspectivas de empleo, así como también la historia conductual $^{82}$. El impacto de la crisis financiera es claramente visible con respecto a la prognosis del ingreso futuro. La evaluación de la capacidad económica debe ser razonablemente documentada y demostrar el correspondiente conservadurismo; el aumento del ingreso futuro debe ser plausible y en concordancia con las normas del sector y del mercado. ${ }^{83}$ Con respecto a la valoración colateral sobre los bienes inmuebles, el Banco Central Europeo señala que toda valoración debe ser desarrollada por tasadores independientes calificados que se guían, entre otras cosas, por la evaluación de solvencia financiera del deudor ${ }^{84}$. También se establece que la valoración de flujos futuros de dinero debe basarse en supuestos "adecuados y realistas". Aquí también debe proveerse de documentación para la valoración.

A pesar de la elaboración de estos principios sustantivos, el Banco Central Europeo está muy preocupado de explicar que su competencia se deriva de sus facultades supervisoras. Claramente establece que "la reducción deliberada y sostenible de los incumplimientos en los balances de los bancos es beneficiosa para la economía tanto desde una perspectiva prudencial micro como macro", ${ }^{85}$ y que los incumplimientos constituyen un riesgo significativo para los bancos del sector europeo. ${ }^{86} \mathrm{Al}$ mismo tiempo, el Banco Central Europeo está muy consciente de que su competencia no incluiría la dictación de directrices obligatorias. Por ello, la NPL Guidance meramente pretende apuntar a las buenas prácticas de los acreedores en sus perspectivas para negar el otorgamiento de crédito, que deben integrar la protección del consumidor en sus estrategias frente a los incumplimientos por parte de las instituciones financieras supervisadas. ${ }^{87}$ Debido al carácter no obligatorio que tiene la guía, tampoco incluye sanciones para el caso de infracción de la guía. Como consecuencia, la protección de los consumidores del sobreendeudamiento no queda garantizada por el control regulatorio y la posible imposición de multas a través de agencias supervisoras sin un derecho individual ejecutable para el consumidor. ${ }^{88}$

\subsubsection{Las evaluaciones de solvencia económica}

En la sección II.2, hemos visto que, aparte de permitir el acceso al mercado de los créditos, las evaluaciones de solvencia tienen un fin protector. Sin embargo, podemos cuestionar si las reglas sobre evaluaciones de la MCD pueden efectivamen-

82 European Central Bank (2017), p. 45.

83 European Central Bank (2017), p. 46.

84 European Central Bank (2017), p. 89.

85 European Gentral Bank (2017), p. 4.

86 European Central Bank (2017), p. 5.

87 European Central Bank (2017), p. 11.

88 Rotт et al. (2011); Rotт (2015), párrafos 78 - 79. 
te prevenir el sobreendeudamiento de los consumidores debido a la falta de medios económicos. Hay vacíos en la protección que residen en la ausencia de sanciones y en la naturaleza misma de las evaluaciones.

A pesar de que la MCD exige a los Estados miembros asegurarse que el acreedor solo otorgue el crédito si la evaluación de solvencia entrega un resultado positivo (artículo 18(5) letra a MCD), lo que implica que el crédito no se otorgará si la evaluación es negativa, se carece de una norma sobre las consecuencias jurídicas que tendría para el acreedor otorgar un crédito ante una evaluación negativa o inexistente. El artículo 38 de la MCD solo establece la fórmula casi estándar (en la legislación de la Unión Europea) de exigir a los Estados miembros determinar "penas efectivas, proporcionadas y disuasivas para el incumplimiento de las normas de la MCD". ${ }^{89}$ Bajo el derecho de la Unión Europea, la pregunta sobre las penas y remedios se encuentra en las manos de los tribunales nacionales, que deben evaluar la eficacia, proporcionalidad y poder disuasorio de las penas nacionales en vista de la MCD. Esto puede que no sea un incentivo suficiente para que los acreedores realicen evaluaciones completas.

A pesar de la existencia de obligaciones de realizar evaluaciones, y aunque los bancos rutinariamente evalúan la solvencia crediticia de sus clientes, la evidencia sugiere que los acreedores no siempre usan su conocimiento para desincentivar la contratación de créditos. $\mathrm{Al}$ contrario, incluso puede que incentiven a deudores de alto riesgo a expandir sus créditos. ${ }^{90}$ La falta de sanciones para el acreedor por no realizar evaluaciones de solvencia puede tener un impacto negativo en la protección de los consumidores, especialmente en el caso de créditos de proporción alta con respecto al valor y deudores de valor neto bajo. Particularmente en los años inmediatamente previos a la crisis financiera, se otorgaron créditos a consumidores de valor neto bajo, aun cuando debería haber sido obvio al momento de celebración del contrato que ellos podrían no ser capaces de pagar el crédito, lo que sugiere que no se realizaron evaluaciones de solvencia, o que los resultados negativos de la evaluación fueron ignorados. ${ }^{91}$ Podemos preguntarnos si el señor Aziz fue sometido o no a una evaluación exhaustiva de solvencia. Seguramente que se le otorgó un crédito en un

89 El carácter disuasivo de las penas era un aspecto importante en el caso Crédit Lyonnais, en el cual la CJEU se pronunció sobre una norma del derecho francés que establecía una pena de falsificación de derecho a obtener crédito si la evaluación crediticia del Consumidor no es evaluada por el acreedor. En el caso, la CJEU considera que no era disuasivo si los montos que recibe el acreedor si el deudor incumple no son significativamente más bajos que sin el incumplimiento (aquí la tasa de interés contractual fue reemplazada por una tasa legal más alta, que en la práctica era más beneficiosa para el acreedor), CJEU 27/03/2014, C-565/12 LCL Le Crédit Lyonnais SA v Fesih Kalhan (2014), ECLI:EU:C:2014:190, párrafos 52 - 53.

90 Atamer (2011), pp. 199 y ss.

91 Véase los informes de los distintos países en Domurath et al. (2014); para Estados Unidos, véase Mian y Sufi (2014). 
clima socioeconómico excesivamente optimista y con otras limitaciones cognitivas, ${ }^{92}$ en el cual los incentivos para la realización de "exhaustivas" evaluaciones no existían o no funcionaban. Está por verse si la MCD cambiará esto en el largo plazo.

Aparte de la falta de sanciones, otra limitación importante de las evaluaciones de solvencia es que ellas por naturaleza son utilizadas al comienzo de la relación entre el acreedor y deudor, antes de que se celebre el contrato de mutuo. Su verdadera función consiste en evaluar si celebrar un contrato o no. Esto implica que los eventos adversos imprevistos que ocurren con posterioridad a la celebración del contrato difícilmente pueden ser considerados. Para estar seguros, algunas disposiciones de la MCD tienen que ver con futuros desarrollos del mercado. El artículo 18(3) de la MCD y el Preámbulo 55 de la MCD reconocen que los precios de las viviendas pueden caer. De acuerdo al artículo 18(3) de la MCD, la evaluación de solvencia no deberá basarse completamente en el valor de la propiedad objeto del contrato, y los Estados miembros deben asegurarse que la tasación de las propiedades para los fines de créditos hipotecarios sean confiables. De manera similar, el artículo 19 de la MCD asegura que la tasación de la propiedad debe ser realizada de conformidad con estándares confiables en los Estados miembros. Estos artículos claramente tienen el propósito de contrarrestar las tasaciones excesivamente optimistas que tuvieron lugar durante la burbuja inmobiliaria antes de la crisis financiera. Por lo tanto, intentan mitigar el impacto de un posible golpe macroeconómico sobre las capacidades de pago de los consumidores. Reconocen que el consumidor que carece de medios económicos no mitiga su falta de capacidad para el pago con los pronósticos económicos exageradamente optimistas.

Más aun, desde un punto de vista técnico, la información que está siendo empleada por las evaluaciones de solvencia económica solo es capaz de modelar una aproximación a la capacidad económica para pagar el crédito que tiene el deudor. Los datos nunca son completos y pueden ser imparciales. ${ }^{93}$ Así como las personas no pueden prever todos los posibles eventos que pueden afectar las capacidades de pago de los deudores, los algoritmos tampoco lo pueden, ya que -después de todo- son programados por personas. Dado que no todos los eventos pueden preverse y calcularse anticipadamente, las evaluaciones de solvencia no son suficientes para asegurar la prevención del sobreendeudamiento.

\subsubsection{Información y educación financiera}

Hemos visto anteriormente que la provisión de información bajo el derecho de la Unión Europea cumple el propósito de poner al consumidor a la par del proveedor durante las negociaciones preliminares. En la industria financiera, esta perspectiva se orienta a la expansión del crédito y el acceso al mercado, pero no hacia las principales causas de insolvencia: los créditos de proporción alta con respecto al valor y

92 Muchos autores han analizado el temerario exceso de confianza y otros sesgos conductuales de los humanos, Sharot (2011), y especialmente de los actos económicos: Jolls et al. (1998), Etzioni (2011), SPINDLER (2011).

93 Ramsay (1995); también: Rona-Tas (2015); Rona-Tas (2008). 
deudores de valor neto bajo, y los eventos adversos imprevistos. La naturaleza misma de las obligaciones de informar es mejorar la transparencia de las transacciones; cualquier efecto protector para los deudores de la insolvencia debido a la falta de medios económicos iniciales o eventos sobrevinientes adversos son incidentales.

Esto no implica que las obligaciones de informar no sean del todo protectoras. Con el objetivo de que la información sea transparente y accesible, se asegura que los consumidores al menos entiendan los términos y condiciones de las obligaciones que adquieren con el crédito. La estandarización de la información contribuye a prevenir el así denominado exceso de información. ${ }^{94}$ Debido a la racionalidad limitada, las personas no pueden procesar una cantidad infinita de información, lo que conduce a una calidad de decisiones disminuida cuando la información alcanza un determinado nivel. ${ }^{95}$ Esto incluso resulta aplicable a los expertos. ${ }^{96}$ Esta sobrecarga de información puede llevar a un aumento en los costos de transacción y hacer que la provisión de información sea contraproductiva ${ }^{97}$ La ESIS de la MCD se centra en 15 tipos de información. Esto no implica recurrir a decenas o más páginas de información a las que usualmente se aluden cuando se habla de información excesiva. Con ello, los consumidores podrían efectivamente ponerse en una situación en la cual serían capaces de comparar información significativa relativa al crédito. De si comprenden o no el impacto que tendría el acuerdo sobre su situación económica en general es una pregunta distinta; pero el foco de la estandarización sobre unos pocos puntos cruciales es generalmente adecuado para contrarrestar la sobrecarga de información.

No obstante, el modelo de información de la Unión Europea puede ser criticado, principalmente debido a las dudas sobre su efectividad. En particular, la investigación de economía conductual [behavioural economics] cuestiona la utilidad de la entrega de información basada en el modelo del actor racional..$^{98}$ La última crisis

94 Para la regulación de los instrumentos financieros en Estados Unidos, véase PAREdes (2003).

95 Paredes (2003), pp. 441 y ss. con respectivas referencias

96 Paredes (2003).

97 SPINDLER (2011), p. 322

98 Los estudios en el ámbito de la economía conductual no son incontrovertidos. La crítica más común tiene que ver con el ámbito estrecho de aplicabilidad de los estudios de la economía conductual específicos de contexto a grupos particulares de consumidores (FAURE y LUTH (2011)). De manera similar, Levine (2009) sostiene que el ámbito de aplicación de la economía conductual es limitado (por ejemplo, para explicar los pánicos grupales) -y que "la gran cantidad de conducta humana" puede ser explicada adecuadamente por el modelo del actor racional-, argumentando con ello a favor de un rol reforzado pero solo de apoyo para la economía conductual. En relación a la crítica desde el ámbito de la sociología económica (v.gr. FreRichs (2011)), que favorece una contextualización de las diferentes "naturalezas" de consumidores en un ambiente cultural, puede decirse que esta crítica no contradice el uso de perspectivas de la economía conductual como tal. En general, uno puede argumentar que las críticas en contra de la economía conductual pueden tomarse en serio sin necesidad de rechazar sus ideas en forma conjunta, FAuRE y LuTH (2011). Debe notarse que en el ámbito de la protección del consumidor, la aplicación de la economía conductual es menos controvertida. De manera tal que, para nuestros propósitos, es suficiente con reconocer la duda que se plantea sobre la medida en la cual los consumidores pueden responder a la eliminación de la asimetría de información. 
financiera ha demostrado una vez más que los individuos no se comportan de la forma racional que asumen las aproximaciones económicas clásicas. ${ }^{99}$ Las limitaciones cognitivas conducen a los individuos a sobreestimar sus capacidades económicas y subestimar la probabilidad de que ocurran eventos adversos que afecten dichas capacidades. Como consecuencia, los efectos de la entrega de información sobre la conducta del consumidor son más bien modestos. ${ }^{100}$

En conclusión, esta perspectiva tiene limitaciones con respecto a cómo los actores racionales efectivamente funcionan. Esto no significa que la información no debiera entregarse, pero que no debiera ser la única herramienta para la protección del consumidor. Más aun, no hay mucha evidencia que sugiera que los consumidores se sobreendeudan debido al exceso de información. Si el objetivo de prevenir la insolvencia y las consiguientes pérdidas de bienestar es tomado en serio, debe ponerse énfasis en herramientas jurídicas distintas.

\subsubsection{El control de cláusulas abusivas}

Ya hemos visto que el control de cláusulas abusivas tiene una importante dimensión del acceso. Al mismo tiempo, la UCTD ha sido una de las directivas más importantes sobre la cual los deudores sobreendeudados han confiado luego de la crisis financiera. Algunos de los casos más importantes de la CJEU han sido fundamentales para cambiar las reglas de los Estados miembros para poder ayudar a los consumidores a lidiar con sus deudas y evitar repercusiones sociales aun más severas. El principal punto ha sido la ejecución de los créditos de consumidores insolventes. Muchos deudores trataron de invocar la UCTD para poder contrarrestar la legislación procesal nacional que percibían como perjudicial para ellos en tanto permitía a los acreedores ejecutar los créditos bajo el cumplimiento de requisitos poco exigentes. Los casos han generado muchos comentarios académicos, debido a su impacto sobre las reglas procesales nacionales, las cuales -bajo el derecho de la Unión Europea- en principio se mantienen bajo la competencia de los Estados miembros conforme al principio de la autonomía procesal nacional.

El caso más importante sobre esto es el ya mencionado $A z i z$, en el cual la CJEU determinó que el derecho procesal español, conforme al cual la ejecución de una hipoteca (que eventualmente llevaría al desalojo del deudor) puede tener lugar sin que sea necesario efectuar un control de cláusulas abusivas del contrato, es contrario a la eficacia del derecho de la Unión Europea. ${ }^{101}$ Debe ser posible para el consumidor que se ejerza un control de cláusulas abusivas por el tribunal durante el proceso de ejecución, para poder evitar la pérdida irreversible de su vivienda, y para que sea eficaz la protección frente a cláusulas abusivas de la UCTD. Después de la decisión en Aziz, el legislador español modificó su legislación procesal, de modo tal que la parte demandada en los procedimientos de ejecución de la hipoteca podría objetar estos procedimientos alegando el carácter abusivo de las cláusulas del contrato en

99 JoLLs et al. (1998).

100 Whitford (1973), mostrando que los efectos pueden limitarse a grupos de ingresos altos.

101 C-415/11 (Aziz), párrafos 57-59. 
cuestión. ${ }^{102}$ Sin embargo, la modificación legislativa dio lugar a nuevos problemas en la ejecución. En Sánchez Morcillo, ${ }^{103}$ la CJEU determinó que el artículo 695 inciso $4^{\circ}$ de la Ley de Enjuiciamiento Givil, conforme al cual un tribunal puede continuar con los procedimientos de ejecución mientras se encuentre pendiente la resolución sobre el posible carácter abusivo de las cláusulas del contrato, establece una ventaja injustificada para el banco a expensas del propietario deudor, porque mientras el banco podría apelar en contra del mantenimiento de la ejecución, el propietario no podría. Se señaló que el derecho procesal español no ofrecía una protección adecuada y eficaz para los propietarios en los términos del artículo 7(1) de la UCT en conjunto con el artículo 47 de la Carta de Derechos Fundamentales de la Unión Europea (ChFR), porque el desbalance entre los derechos procesales disponibles para el consumidor, por una parte, y el deudor por la otra "acentúa el desbalance existente entre las partes", en términos del poder de negociación y el nivel de conocimiento. ${ }^{104}$ Esta infracción al principio de igualdad procesal -el balance de las armas en los derechos de ejecución- pone en riesgo la eficacia de la UCTD.

Ello, junto con jurisprudencia posterior de la CJEU, ha atraído comentarios académicos significativos en Europa. La CJEU es al mismo tiempo alabada y criticada por su "activismo judicial", y su conciencia social e innovación legal. ${ }^{105}$ En el caso Aziz, la CJEU estableció claramente que la importancia de la propiedad adquirida como vivienda familiar debe jugar un rol en el control de cláusulas abusivas. ${ }^{106} \mathrm{De}$ manera similar, la Corte estaba consciente en Sánchez Morcillo de las consecuencias significativas de su decisión en España, donde muchas personas durante años recientes han sido objeto de procesos de ejecución respecto de sus propias residencias. ${ }^{107}$ Más aun, la CJEU tuvo en cuenta que el riesgo de perder su vivienda pone al consumidor y su familia en una "situación particularmente frágil". ${ }^{108}$ Estas intervenciones muestran que la Corte tiene una cierta conciencia social y societaria, al intervenir significativamente en los ordenamientos jurídicos de los Estados miembros.

Sin perjuicio de ello, desde la perspectiva adoptada en este trabajo, el control de cláusulas abusivas no resulta suficiente para proteger a los deudores de las dos principales causas de insolvencia. Lo anterior se debe a que la UCTD no está preocupada de un tipo sustantivo de cláusula abusiva. No indica cómo debiera estar redactado un contrato de consumo "no abusivo". Esto se refleja en el artículo 4

102 Capítulo III de la Ley 1/2013 de 2013 modificó la Ley de Enjuiciamiento Civil de 2000, que también fue modificada por el Decreto Ley 7/2013 de 2013.

103 GJEU 14/07/2014, C-169/14 Juan Carlos Sánchez Morcillo and María del Carmen Abril García v Banco Bilbao Vizcaya Argentaria SA (2014), ECLI:EU:C:2014:2099.

104 G-169/14 (Sánchez Morcillo), párrafos 46, 50 - 51.

105 Por ejemplo Micklitz (2013); Micklitz y Reich (2014); Della Negra (2015); Iglesias Sánchez (2014).

106 G-415/11 (Aziz), párrafos 60-61.

107 C-169/14 (Sánchez Morcillo), párrafo 7.

108 G-169/14 (Sánchez Morcillo), párrafo 11. 
UCTD. En primer lugar, el artículo 4 (2) de la UCTD establece que el objeto principal del contrato, incluyendo si se trata de un precio justo, no forma parte del control de cláusulas abusivas, siempre que las cláusulas que establezcan el precio sean transparentes e inteligibles. ${ }^{109}$ Esto significa que los deudores no están protegidos de obligarse a préstamos que no pueden pagar. En vez de adoptar un modelo de equidad que podría, por ejemplo, tomar en cuenta los montos de las cuotas mensuales o la duración del período de pagos, se asume que el carácter abusivo del contrato deriva exclusivamente del hecho que el deudor no podría negociar los términos del contrato. De manera tal que para que la UCTD se aplique en $A z i z$, no importa por qué el señor Aziz incumple desde un comienzo. Y en segundo lugar, incluso si el incumplimiento ocurre como consecuencia del carácter abusivo del contrato, nos enfrentamos igualmente a otro problema. De acuerdo al artículo 4 (1) de la UCTD, el control de cláusulas abusivas se basa en las circunstancias existentes al momento de la celebración del contrato. Esto significa que las circunstancias que ocurren con posterioridad a la celebración del contrato no juegan rol alguno en el control de cláusulas abusivas, con lo cual se omite considerar los factores que podrían en efecto convertir las cláusulas del contrato en abusivas después de considerar la situación actual del consumidor (o profesional, para estos propósitos). Por consiguiente, los eventos imprevistos como la pérdida del empleo, no pueden ser considerados en los controles de cláusulas abusivas.

De esta manera, la UCTD, de una manera formalista, pretende la restauración del balance de poder de negociación al tiempo de celebración del contrato. Pero remediar una posición asimétrica de negociación entre consumidores y proveedores no es una aproximación sustantiva para controlar el equilibrio contractual en los contratos. ${ }^{110}$ Se basa en la premisa según la cual los actores encontrándose en una posición de igualdad para negociar, van a negociar un contrato que es justo para sus estándares. Sin perjuicio de la incontrovertida conciencia social de la CJEU, la perspectiva de conectar los procedimientos de ejecución con el control de cláusulas abusivas de los contratos no protege a los propietarios de incumplir sus préstamos, con independencia de si contienen o no cláusulas abusivas. Debemos tener en cuenta que, a fin de cuentas, Mohammed Aziz, como tantos otros, perdió su vivienda a pesar del activismo judicial de la GJEU.

109 Para una discusión, véase CJEU 30/04/2014, C-26/13 Árpád Kásler, Hajnalka Káslerné Rábai v OTP Felzálogbank Zrt (2014), ECLI:EU:C:2014:282 (Kásler), párrafos 32-34.

110 Esto, por supuesto, está relacionado con el asunto de la competencia de la CJEU para asegurar la interpretación y aplicación del derecho de la Unión Europea, artículo 19 del Tratado de la Unión Europea (TEU), el cual es, a pesar de la significativa intervención a través de los principios de la Unión Europea de equivalencia y eficacia, restringido por la autonomía procesal de los Estados miembros y la restante competencia de los Estados miembros para sus reglas contractuales. Véase Domurath (2017), p. 103. 


\subsection{Conclusiones provisorias}

Hemos visto que el marco regulatorio de la Unión Europea está más orientado a brindar acceso al mercado financiero por sobre la protección de los deudores frente a la insolvencia.

En primer lugar, las normas sobre evaluaciones de solvencia económica pasan por alto limitaciones conductuales y legales, en particular los sesgos inherentes de cualquier tipo de instrumento dirigido tecnológicamente, ${ }^{111}$ y la falta de sanciones por no tomar en cuenta los resultados de las evaluaciones. La crisis financiera ha demostrado que las normas sobre evaluaciones de solvencia pueden ser fácilmente ignoradas. Como consecuencia, la capacidad económica de pago de los deudores no siempre se evalúa adecuadamente, y por tanto el crédito puede otorgarse a pesar de la falta de medios económicos. En segundo lugar, la perspectiva principal del derecho de consumo de la Unión Europea de otorgar información a los deudores tampoco tiene que ver con la protección; su verdadera esencia radica en situar al consumidor a la par del proveedor durante el proceso de negociación del contrato, reforzando con ello la posición del consumidor para el acceso al mercado de los créditos y para elegir entre los productos financieros y, de esta forma, favorecer la competencia en el mercado interno de la Unión Europea. El principal problema aquí es que la situación económica de los deudores no juega un rol. En tercer lugar, el control de oficio de cláusulas abusivas no es, a pesar de estar dirigido por la evidente preocupación social de la CJEU, apropiado para la protección de los deudores hipotecarios que incumplen debido a la falta de medios económicos o el advenimiento de eventos imprevistos. Respecto del primer problema, la UCTD no extiende el control de cláusulas abusivas a las cláusulas de transparencia del precio (artículo 4 (2) UCT); respecto del segundo, el control de cláusulas abusivas se relaciona solo con las circunstancias existentes al momento de celebración del contrato (artículo 4 (1) UCT). Esto excluye la posibilidad de un ajuste del contrato basado bajo la perspectiva de la teoría de la imprevisión, lo cual permitiría a los deudores renegociar sus obligaciones financieras del contrato dadas sus nuevas capacidades financieras, modificadas. ${ }^{112}$

Sobre este punto, el marco regulatorio de la Unión Europea podría buscar inspiración en las teorías actuales de la imprevisión, que forman parte de la mayoría de los códigos civiles a lo largo de Europa, incluso siendo aplicables a circunstancias excepcionales. Las normas más amplias que aplican esta teoría pueden encontrarse en los sistemas jurídicos nórdicos, en los cuales los jueces pueden alterar los términos de los contratos como un asunto de equidad. ${ }^{113}$ La Corte Suprema de Portugal también ha aplicado el principio del rebus sic stantibus a un contrato de modificación de la tasa de

111 Sobre las evaluaciones de solvencia, véase: RAMSAY (1995); de forma más general: Koops (2011), LeEse (2014). Para una interesante y charla accesible de Joy Buolamiwini, Buolamiwini (2016).

112 Esta es una posibilidad especialmente en el artículo 36 de los Contract Acts of the Nordic Countries. Para una discusión sobre esto, véase Wilhelmsson (1990); Wilhelmsson (1993), p. 440 con más referencias; HÄYнÄ (1994); Momberg Uribe (2011); Domurath (2017).

113 Para una discusión, véase Wilhelmsson (1990); HÄyнä (1994); Momberg Uribe (2011); Domurath (2017). 
interés que se suponía iba a mitigar los riesgos involucrados en un contrato de mutuo con un interés variable vinculado al interés Euribor. ${ }^{14}$ La crisis financiera definitivamente ha revivido los debates sobre la teoría de la imprevisión a lo largo de Europa. ${ }^{115}$

\section{EL GASO GHILENO: ¿DE LAS GRISIS FINANGIERAS A LA MEJOR PROTEGGIÓN DE LOS DEUDORES?}

En esta última sección, veremos cómo un marco regulatorio fuera de la Unión Europea aborda el problema del acceso a los créditos hipotecarios y el mercado inmobiliario, y la protección de los deudores hipotecarios. Veremos que surge una perspectiva diferenciada que, a pesar de ser similar en su aproximación, no es idéntica a la protección que reciben los deudores hipotecarios en la Unión Europea.

\subsection{La vivienda en Chile y las políticas de hipotecas: La expansión en el acceso}

En Chile, la política sobre la vivienda fue distinta a los desarrollos del sector inmobiliario en Europa y Estados Unidos, pero siguió en términos generales la misma tendencia en términos del énfasis en los mercados privados y el mercado financiero. En el pasado, Chile había elaborado un sistema financiero relativamente estable, en el cual el gobierno intervino poderosamente en tiempos de depresión e inestabilidad. ${ }^{116} \mathrm{El}$ otorgamiento de terrenos para viviendas por el Estado era dirigido a los más pobres, quienes tenían que luego construirse sus propias casas en el sitio (la política fue descontinuada durante el gobierno de Allende por razones ideológicas). A partir de la década de 1950, los subsidios estatales y la expropiación dominaron el sector inmobiliario. ${ }^{117}$ Durante la década de 1970, incluso antes que la privatización tomará fuerza en otros ámbitos, el general Pinochet, que obtuvo el poder a través de un golpe de Estado el 11 de septiembre de 1973, comercializó incrementalmente el sector inmobiliario. ${ }^{118}$ De hecho, el régimen de Pinochet estaba al frente de los esfuerzos de marketización y privatización en Latinoamérica con respecto a políticas como la salud, educación y servicios públicos. Chile era considerado como un laboratorio para las políticas neoliberales que luego serían adoptadas en otros países de Latinoamérica, así como también en el Reino Unido y Estados Unidos. ${ }^{19}$

Posteriormente, especialmente a partir de las políticas de principios de la década de 1980, todo en Latinoamérica se orientó al mercado, políticas en gran medida incentivadas y exigidas por el Banco Mundial. ${ }^{120}$ Estos desarrollos favorecieron los

114 Decisión del Supremo Tribunal de Justicia de 10 de octubre de 2013. Debe notarse que existen otras decisiones, en las cuales la Corte Suprema negó la existencia de "imprevisión"; véase CosTa E Silva y Henriques, p. 11. Para una discusión de otros casos, véase Domurath (2017), pp. 112 y ss.

115 Para una discusión véase Momberg Uribe (2011); Domurath (2017).

$116 \operatorname{BROCK}(2000)$, pp. 73-74.

117 Richards (1995), p. 522.

118 Véase Long (2016).

119 Prieto Larraín (2011), p. 104.

120 Clegg (2017), pp. 69-70. 
derechos de propiedad individuales y el desarrollo del mercado privado, apoyado por la teoría económica del libertarismo, altamente influyente en Latinoamérica, el economista neoliberal peruano De Soto y los llamados Chicago Boys, quienes influyeron en la política de Pinochet de abogar por el abandono de las políticas económicas estructurales y el establecimiento de mercados desregulados. ${ }^{121}$ En concordancia con el pensamiento neoliberal, el Estado chileno comprendió su rol como uno subsidiario, enfocándose en la política social solo para las familias más pobres del país. ${ }^{122}$

Bajo una perspectiva pragmatista neoliberal que buscaría la legitimación de un gobierno militar tecnocrático, ${ }^{123}$ la regulación de los mercados financieros en Chile fue de la mano con un aumento en la privatización y la expansión de los créditos hipotecarios a partir de mediados de la década de 1970. El gobierno eliminó los controles a las tasas de interés y liberalizó el sector bancario, de modo tal que más instituciones financieras pudieran ingresar al mercado de los créditos. ${ }^{124} \mathrm{La}$ herramienta principal para que los ciudadanos accedieran a las viviendas eran subsidios directos y dependientes del nivel de recursos para los más pobres, otorgando hasta el 75 por ciento del valor de la vivienda en subsidios, siendo el saldo restante financiado mediante una hipoteca estatal a una tasa de interés fija. En estos tiempos, los mercados hipotecarios se expandieron significativamente. La expansión de las instituciones financieras en el comercio, inversión, préstamos hipotecarios y fondos de pensiones llevaron a una profundización de los créditos bancarios y los mercados de capitales.

Sin embargo, el sistema financiero chileno pronto debió enfrentar una crisis, no muy distinta a la estadounidense de 2008. La expansión masiva del crédito, junto con la falta de regulación y supervisión prudencial, y exacerbado por problemas estructurales debido a la conglomerización opaca del sector bancario, condujo a burbujas de activos. ${ }^{125} \mathrm{El}$ gobierno intervino con paquetes de rescates y una reestructuración profunda del sistema financiero chileno. Se empleó una estrategia triple, que incluía una reestructuración de deudas para deudores comerciales e hipotecarios, la compra a instituciones financieras de préstamos no cobrados, y la venta, fusión o liquidación de instituciones insolventes. ${ }^{126}$ Luego, en 1986, el gobierno dictó la Ley General de Bancos (LGB), que intentó establecer un camino intermedio entre una regulación prudencial poderosa y una economía de mercado. ${ }^{127}$ La nueva LGB introdujo la figura del préstamo o mutuo hipotecario endosable, reemplazando las hasta entonces do-

121 VALDÉs (2008).

122 Gil MaCawley (por aparecer), pp. 25-26.

123 Silva (1991); Prieto Larraín (2011), pp. 122-124, disponible en: https://openaccess.leidenuniv. $\mathrm{nl} /$ bitstream/handle/1887/18141/03.pdf?sequence $=13$.

124 Alvayay y Schwartz (1997), p. 49.

125 HoRnBeck (2009), p. 8.

126 HoRnBeck (2009), p. 9.

127 HornBeck (2009), p. 9. 
minantes letras hipotecarias. ${ }^{128}$ Con ello, la securitización en Latinoamérica aumentó rápidamente durante principios de 2000, pero se frenó al poco tiempo después. ${ }^{129}$

La narrativa en Chile para la expansión del crédito y el dominio privado de la vivienda es similar a la "democratización del crédito" en Estados Unidos y las políticas financieras y sociales de inclusión en Europa. En Chile, la vivienda propia se convirtió en un "augurio de prosperidad". ${ }^{130} \mathrm{Al}$ igual que en Estados Unidos y Europa, la expansión del crédito fue de la mano con hacer responsables a los ciudadanos de su propio bienestar en una economía política, en el cual los Estados deben jugar solo un rol residual. En Chile, el crédito también se ha convertido en una forma de gobierno ${ }^{131}$ y de gobernabilidad. ${ }^{132} \mathrm{Al}$ mismo tiempo, en el sector inmobiliario hay un fuerte énfasis en la política para favorecer las viviendas sociales. El marco regulatorio general otorga una protección fuerte para los derechos de propiedad y un ambiente favorable a los negocios para los desarrollos y negocios inmobiliarios, una aproximación de "mercados facilitadores". ${ }^{133}$

\subsection{La protección de los deudores hipotecarios: Diferencias y similitudes con el derecho de la Unión Europea}

La diferencia principal entre la regulación chilena de los préstamos hipotecarios y la regulación europea o estadounidense parece ser un marco regulatorio estricto sobre la proporción del crédito con el valor neto de la propiedad, y las políticas especiales para propietarios de bajos ingresos. Actualmente, estos propietarios pueden adquirir viviendas casi completamente sobre la base del subsidio estatal y un pequeño porcentaje de ahorros personales, cerca de un 5 por ciento del monto del subsidio. Esto, en esencia, constituye el otorgamiento de viviendas gratis para familias de bajos ingresos. ${ }^{134}$ Esta política fue implementada luego de una ola sustancial de incumplimientos de créditos hipotecarios por propietarios de bajos ingresos. ${ }^{135}$ La política chilena sobre los propietarios de ingresos medios también se basa en un programa de subsidios estatales, bajo el cual los propietarios que son elegibles reciben certificados que deben complementar con ahorros personales y un crédito hipotecario. ${ }^{136}$

128 Micco et al. (2012), pp. 11-12.

129 Scatigna y Tovar (2007). Sin embargo, también en Chile, donde la crisis financiera tuvo un impacto menor y el sistema financiero es considerado como relativamente estable, el porcentaje de préstamos no pagados ha aumentado, véase https://www.theglobaleconomy.com/Chile/Nonperforming_loans/.

130 Richards (1995), p. 526.

131 Lazzarato (2015).

132 GonzÁlez (2018).

133 Gil McGawley (por aparecer), pp. 37 y ss.

134 Gil McCawley (por aparecer), p. 34.

135 Gil MaCawley (por aparecer), p. 34, nota 121.

136 See Simian (2010), pp. 288-293. 
La perspectiva regulatoria relativa a las normas sobre evaluaciones de solvencia financiera parecen ser más estrictas que en el derecho de la Unión Europea. De acuerdo al artículo $84 \mathrm{~N}^{\circ} 1$ de la LGB, un banco no podrá otorgar préstamos directa o indirectamente por un monto que exceda el 10 por ciento de su valor neto real. En caso de infracción a esta norma, el banco será penado con una multa equivalente al 10 por ciento de este monto (artículo $84 \mathrm{~N}^{\circ} 1$ letra d), párrafo $6^{\circ}$ de la LGB). A pesar de que esto puede no ser una sanción demasiado alta, si se incurre por un número alto de préstamos individuales (por ejemplo, si otorgar créditos por sobre los límites es una práctica estructural), esta norma no tiene un equivalente en el derecho de la Unión Europea. Más aun, las instituciones financieras deben asegurarse que las cuotas mensuales de pagos no excedan el 20 por ciento del ingreso familiar. ${ }^{137}$ Esto demuestra que hay un mayor énfasis en el control ex ante de los préstamos hipotecarios en el marco regulatorio chileno. El legislador no ha dudado en establecer limitaciones para el otorgamiento de créditos. Aquí, Mohammed Aziz no habría podido acceder al crédito.

A primera vista, esto pareciera implicar que a través de una perspectiva regulatoria fuerte, el sistema chileno es más adecuado para proteger a los deudores del sobreendeudamiento. Sin embargo, es necesaria una nota de cautela; esto no significa que la política hipotecaria chilena haya sido exitosa en general. Las tasas de endeudamiento en Chile han alcanzado un registro histórico. ${ }^{138}$ Hay un conflicto actual entre el gobierno chileno y los propietarios sobreendeudados, quienes abogan por la remisión de sus créditos. ${ }^{139}$ Adicionalmente, reconociendo los logros que implica el otorgar su vivienda propia a grandes cantidades de la población de bajos recursos, se ha demostrado que la política chilena de vivienda refuerza la desigualdad social y geográfica. Desde una perspectiva de planificación urbana, el régimen chileno facilitador de vivienda ha fracasado en generar una inclusión urbana. Esto se debe a que el Gobierno ha concentrado las familias de bajos ingresos en áreas de terrenos de valor bajo, los cuales típicamente carecen de acceso adecuado a bienes privados y públicos, como oportunidades laborales, escuelas de calidad o transporte público, reforzando con ello una fuerte "discriminación espacial". ${ }^{140}$

Con respecto a la protección frente a eventos adversos sobrevinientes, el marco regulatorio chileno no es más protector que el europeo. De hecho, en Chile no es habitual que se intervenga en el equilibrio contractual del préstamo. Al igual que sus colegas en Europa, los jueces en Latinoamérica tienden a ser reticentes a interferir con los contratos. ${ }^{141}$ La doctrina clásica y jurisprudencia chilenas son formalistas y positivistas, rechazando el uso de "conceptos genéricos" y "consideraciones exter-

137 RichaRds (1995), p. 524.

138 Banco Central de Chile (2018).

139 Gasgrain (2010).

140 GIL McGawley (por aparecer), pp. 45 y ss.

141 Rubim Borges Fortes (2016), p. 290. 
nas". ${ }^{142}$ La Corte Suprema chilena por mucho tiempo ha establecido que los tribunales no están facultados para desconocer o revisar las cláusulas de los contratos, reforzando con ello la santidad de los contratos. ${ }^{143}$ En doctrina, el principio del pacta sunt servanda del artículo 1545 del Código Civil chileno es considerado como un obstáculo insuperable para la aceptación de la teoría de la imprevisión, que solo una norma legal expresa podría abolir. ${ }^{144}$ Aun más, en el contexto de las relaciones contractuales, los acreedores están protegidos frente a cualquier posible reforma legislativa porque también gozan de una protección constitucional expresa como titulares del derecho de propiedad sobre sus créditos, conforme al artículo 19 No 24 de la Constitución Política chilena, con lo cual cualquier reforma legislativa que implique un cambio de las cláusulas del contrato de cualquier forma que restrinja sus derechos sería inconstitucional. ${ }^{145}$ De modo tal que el hecho que Mohammed Aziz no podría continuar pagando su crédito porque perdió su empleo no tendría tampoco importancia alguna para el derecho chileno.

Sin embargo, al igual que en las discusiones en Europa, la posibilidad de alguna perspectiva de la imprevisión ha sido planteada tanto por la doctrina moderna como, aunque algo aislada, la jurisprudencia. Basada en la doctrina francesa de la imprevisión, la Corte de Apelaciones de Santiago reconoció que el equilibrio contractual había sido gravemente alterado por circunstancias inesperadas, que eran desconocidas para las partes al momento de celebración del contrato, y que cambió la interpretación de la voluntad de las partes. ${ }^{146}$ Esto ha llevado definitivamente a discusiones acerca de la teoría de la imprevisión en el derecho chileno. ${ }^{147}$

Independiente de casos específicos, respecto de los contratos de larga duración como las hipotecas, los ordenamientos jurídicos tanto de la Unión Europea como de Chile no contemplan ajustes en las obligaciones de los deudores luego que un evento adverso ha cambiado la capacidad económica de pago de los deudores. En la Unión Europea, esto se deja a criterio de los distintos Estados miembros, los cuales -al igual que en el caso de Chile- luchan por encontrar un balance adecuado entre el pacta sunt servanda y alguna forma del rebus sic stantibus.

\section{GONGLUSIONES}

En este artículo hemos revisado la ideología de la propiedad sobre la vivienda y el acceso al crédito hipotecario en los respectivos marcos regulatorios. En contra de un contexto de creciente privatización y una retirada de los estados de bienestar,

142 Momberg Uribe (2011), p. 98.

143 Momberg Uribe (2011), p. 109 con referencia a la Gaceta de los Tribunales de 1925, l.er Sem., p. 23. RDJ, T. 23, sec. 1, p. 423 (sentencia de 10 enero de 1925).

144 Momberg Uribe (2011), p. 100.

145 Momberg Uribe (2011), p. 101.

146 Guillermo Larraín Vial con Servicio de Vivienda y Urbanización de la Región Metropolitana (2006).

147 RodríGuez (2007). 
la propiedad privada sobre la vivienda se ha convertido en una institución social importante en la vida moderna. Los Estados han utilizado sus poderes regulatorios para dar lugar a marcos regulatorios que permitan la expansión de los mercados de vivienda privada.

La herramienta principal para esta expansión es el acceso al financiamiento hipotecario, para que la expansión de los mercados financieros incluya cada vez a más deudores hipotecarios. Para este fin, los Estados deben buscar activamente desregular y flexibilizar los mercados financieros (a nivel macro) para poder permitir la innovación financiera. Una de tales innovaciones, la securitización, ha sido vital para la expansión masiva de los créditos hipotecarios antes de la última crisis financiera de 2008. Al mismo tiempo, el derecho contractual (a nivel micro) enfatiza la responsabilidad individual y la transparencia de la información. Sin embargo, hemos visto que hay una contradicción inherente en el acceso al financiamiento hipotecario para el propósito de aumentar el bienestar individual porque la expansión del crédito a más y más segmentos de la sociedad necesariamente implica extender el crédito a más y más deudores con malos registros de crédito. Estos deudores tienen mayores probabilidades de incumplir sus préstamos hipotecarios y, al final, ser desalojados de sus viviendas. Por lo tanto, se argumenta que las reglas que buscan favorecer la expansión de los mercados de financiamiento hipotecario deben también incluir mecanismos de protección para prevenir que los deudores incumplan.

Nuestro análisis de la MCD y la UGTD muestra que los mecanismos de protección están subdesarrollados, en contraste con las normas que buscan expandir el acceso al crédito. Hemos identificado tres problemas principales. En primer lugar, hay inherentes sesgos en las evaluaciones de solvencia económica, así como también una falta de sanciones por ignorar historiales negativos de crédito, lo que conduce a una falta de protección de los consumidores que no tienen suficientes medios económicos. En segundo lugar, hay un énfasis en la entrega de información, lo cual no obstante no toma en cuenta las tendencias conductuales de los actores no racionales. Y en tercer lugar, el control de cláusulas abusivas, usada de manera importante por la CJEU para forzar a los Estados miembros para que protejan a los propietarios que enfrentan desalojos, no se orienta a la prevención del sobreendeudamiento. El precio del crédito se mantiene fuera del ámbito de aplicación de la UCTD, mientras sea fijado de una manera transparente, y la evaluación del carácter abusivo de una cláusula solo se relaciona con las circunstancias existentes al momento de la celebración del contrato. Como consecuencia, los eventos adversos, que alteran negativamente la capacidad económica de pago del deudor, no forman parte del control de cláusulas abusivas.

Entonces, ¿qué habría pasado si Mohammed Aziz hubiese sido chileno? Puede que el señor Aziz no hubiese obtenido el crédito que obtuvo del banco español. El marco regulatorio chileno es más fuerte con respecto a la supervisión de las evaluaciones de solvencia económica, porque contiene límites precisos y sanciones. Esta aproximación parece reconocer que alguna exclusión al crédito puede ser necesaria para proteger a los deudores del sobreendeudamiento. Para los "pobres", el gobierno chileno entonces ofrece otros medios para acceder a la propia vivienda. Esto implica la transformación del acceso a los créditos hipotecarios en políticas inmobiliarias más 
amplias. En relación al reconocimiento de eventos adversos sobrevinientes, el sistema jurídico es tan rígido como el derecho de la Unión Europea. El señor Aziz -una vez que hubiese obtenido el crédito- no habría estado mejor protegido bajo el derecho chileno luego de perder su empleo. Ambos sistemas jurídicos tiene problemas al lidiar con el reconocimiento de que los consumidores pueden sorpresivamente ver reducidas extremadamente sus capacidades de pago. El principio del pacta sunt servanda se mantiene fuerte incluso en casos de fuertes dificultades económicas (y sociales). Este artículo podría dar algún lugar a ideas tendientes a relajar los requisitos para una perspectiva de imprevisión o cambio de circunstancias, en los casos en los cuales se ven involucradas las viviendas de los individuos y sus familias. 


\section{BIBLIOGRAFÍA CITADA}

Aalbers, Manuel B. (2012). Subprime Cities - The Political Economy of Mortgage Markets (Wiley-Blackwell).

Acemoglu, Daron; Ozdaglar, Asuman y Tahbar-Salehi, Alireza (2015). "Systemic Risk and Stability in Financial Networks", American Economic Review, Vol. 105, No 2, pp. 564-608.

Alcalde Rodríguez, Enrique (2007). "Corte de Apelaciones de Santiago y Teoría de la Imprevisión. Un Hito Fundamental en la Evolución de Nuestra Justicia Ordinaria", Revista Chilena de Derecho, Vol. 34, № 2, pp. 361-372.

Alvayay, Jaime R. y Schwartz, Arthur L. (1997). "Housing and Mortgage Market Policies in Chile", Gournal of Real Estate Literature, Vol. 55, N 5, pp. 47-55.

Anderson, Miriam y Arroyo Amayuelas, Esther (2018). The Impact of the Mortgage Credit Directive in Europe - Contrasting Viewes from Member States (Europa Law Publishing).

Atamer, Yesim M. (2011). "No Duty of Responsible Lending: Should the European Union Take Action?", in Grundmann, Stefan y Atamer, Yesim M. (eds.), Financial Services, Financial Crisis and General European Contract Law (Wolters Kluwer), pp. 179-202.

BECKerT, Jens (2019). "The exhausted futures of neoliberalism. From promissory legitimacy to social anomy", fournal of Cultural Economy. DOI: 10.1080/17530350.2019.1574867.

Beckert, Jens (2016). Imagined Futures - Fictional Expectations and Capitalist Dynamics (Harvard University Press).

Beckert, Jens (2013). "Capitalism as a System of Expectations: Toward a Sociological Microfoundation of Political Economy", Politics and Society, Vol. 41, N 3, pp. 323-350.

Brock, Philip L. (2000). "Financial Safety Nets: Lessons from Chile", The World Bank Research Observer, Vol. 15, N 1, pp. 69-84.

Buck, Tobias (2013). "EU court strikes down Spain's eviction law", Financial Times, 14 de marzo de 2014, en: www.ft.com/intl/cms/s/0/16e37aca-8ca5-11e28ee0-0144feabdc0.html\#axzz3buvOJuPd

Buolamiwini, Joy (2016). "How I'm fighting bias in algorithms", in: https://www. ted.com/talks/joy_buolamwini_how_i_m_fighting_bias_in_algorithms?referrer=playlist-the_inherent_bias_in_our_techn. 
Cartwright, Peter (2012). "The Vulnerable Consumer of Financial Services: Law, Policy and Regulation", en: https://www.nottingham.ac.uk/business/businesscentres/gcbfi/documents/researchreports/paper78.pdf.

Casgrain, Antoine (2010). "La apuesta del endeudamiento en la política habitacional chilena", Revista INVI, Vol. 25, Issue 68, pp. 155-182.

Castles, Francis G. (1998). "The Really Big Trade-Off: Home Ownership and the Welfare State in the New World and the Old", Acta Politica, Vol. 33, Issue 1, pp. 5-19.

Castles, Francis G.; Leibfried, Stephan; Lewis, Jane; Obinger, Herbert y Pierson, Christopher (2010). "Introduction", en mismos autores (eds.), Oxford Handbook of the Welfare State (Oxford University Press), pp. 1-15.

Clegg, Liam (2017). The World Bank and the Globalization of Housing Finance: Mortgaging Development (Edward Elgar Publishing).

Comparato, Guido (2018). The Financialisation of the Citizen - Social and Financial Inclusion through European Private Law (Hart Publishing Ltd).

Comparato, Guido (2015). "The rationales of financial inclusion in the changing European private law", European Review of Contract Law, Vol. 11, Issue 1, pp. 22-45.

Comparato, Guido y Domurath, Irina (2015). "Financialisation and its implications for private autonomy in consumer credit law", Osservatorio del Diritto Civile e Commerciale, $\mathrm{N}^{\circ} 1 / 2015$, pp. 269-288.

Conley, Dalton y Gifford, Brian (2006). "Home Ownership, Social Insurance, and the Welfare State", Sociological Forum, Vol. 21, N 1, p. 55-82.

Costa e Silva, Paula y Henriquez, Duarte (2016). "Arbitration in swaps: The Portuguese experience", Arbitration International, pp. 1-25.

Crouch, Colin (2009). "Privatised Keynesianism: An unacknowledged policy regime", British Fournal of Politics and International Relations, Vol. 11, Issue 3, pp. 382-399.

Della Negra, Federico (2015). "The uncertain development of the case law on consumer protection in mortgage enforcement proceedings: Sánchez Morcilla and Kusionová”, Common Market Law Review, Vol. 52, Issue 4, pp. 1009-1032.

Desmond, Matthew (2017). Evicted - Poverty and profit in the American City (Penguin Random House LLG).

Domurath, Irina (2017). Consumer Vulnerability and Welfare in Mortgage Contracts (Hart Publishing).

Domurath, Irina (2013). "The Case for Vulnerability as the Normative Standard in European Consumer Credit and Mortgage Law - An Inquiry into the Paradigms of Consumer Law", Fournal of European Consumer and Market Law, Vol. 2, Issue 3, pp. 124-137. 
Domurath, Irina; Comparato, Guido y Micklitz, Hans W. (eds.) (2014). The Over-indebtedness of European consumers: A View from six countries (European University Institute).

ECGG Plenary (2013). European Consumer Consultative Group Opinion on consumers and vulnerability.

Edgar, Bill; Doherty, Joe y Meert, Hendrik (2002). Access to Housing : Homelessness and Vulnerability in Europe (Bristol Policy Press).

Etzioni, Amitai (2011). "Behavioural Economics: Next Steps", Fournal of Consumer Policy, Vol. 34, Issue 3, pp. 277-287.

European Central Bank (2017). Guidance to banks on non- performing loans.

European Commission (2007). White Paper on the Integration of EU mortgage Credit Markets, COM (2007) 807 final, Brussels, 18.12.2007.

European Commission (2005). Green Paper Mortgage Credit in the EU, COM (2005) 327 final, Brussels, 19.7.2005.

European Commission (1993). Action plan 1993-1995 'Placing the Single Market at the Service of European consumers', COM (93) 378 final, Brussels, 23.07.1993.

Faure, Michael G. \& Luth, Hanneke A. (2011). "Behavioural Economics in Unfair Contract Terms", Fournal of Consumer Policy, Vol. 34, Issue 3, pp. 337-358.

FerRetti, Federico (2010). "A European perspective on consumer loans and the role of credit registries: The need to reconcile data protection, risk management, efficiency, over-indebtedness, and a better prudential supervision of the financial system", fournal of Consumer Policy, Vol. 33, Issue 1, pp. 1-27.

Fuigstein, Neil y Habinek, Jacob (2014). "Sucker punched by the invisible hand: the world financial markets and the globalization of the US mortgage crisis", Socio-Economic Review, Vol. 12, Issue 4, pp. 637-665.

Frerichs, Sabine (2011). "False Promises? A Sociological Critique of the Behavioural Turn in Law and Economics", fournal of Consumer Policy, Vol. 34, Issue 3, pp. 289-314.

Friedman, Milton (2002). Capitalism and Freedom, (University of Chicago Press, $40^{\text {th }}$ Anniv. ed.).

Fulcher, James (2004). Capitalism - A very short introduction, (Oxford University Press).

GIL MaCawley, Diego (por aparecer). Law and Inclusive Urban Development: Lessons from Chile's Enabling Markets Housing Policy Regime.

GonzÁlez LóPez, Felipe (2018). "Crédito, deuda y gubernamentalidad financiera en Chile", Revista Mexicana de Sociología, Vol. 80, № 4, pp. 881-908.

Gotham, Kevin Fox (2012). "Creating Liquidity Out of Spatial Fixity - The Secondary Circuit of Capital and the Restructuring of the US Housing Finance System”, en Aalbers, Manuel (ed.) Subprime Cities - The Political Economy of Mortgage Markets (Wiley-Blackwell), pp. 25-52. 
Harloe, Michael (1995). The Golden Age : Social Housing in an Era of Reconstruction and Growth (Blackwell Publishing Ltd).

НйҮнӓ, Juha (1994). "Scandinavian Techniques for Controlling Fairness in Contracts", en Brownsword, Roger; Howells, Geraint G. y Wilhelmsson, Thomas (eds.), Welfarism in Contract Law (Ashgate), pp. 127-157.

Hellwig, Martin F. (2009). "Systemic Risk in the Financial Sector: An Analysis of the Subprime-Mortgage Financial Crisis", De Economist, Vol. 157, Issue 2, pp. 129-207.

Hondius, Ewoud (2004). "The Protection of the Weak Party in a Harmonised European Contract Law: A Synthesis", fournal of Consumer Policy, Vol. 27, Issue 3, pp. 245-251.

Hornbeck, John F. (2009). "Financial Regulation and Oversight: Latin American Financial Crises and Reform Lessons from Chile" (Congressional Research Service).

Huffschmid, Jörg (2009). "Finance as Driver of Privatisation", en Frangakis, Marica et al. (eds.) Privatisation against the European Social Model - A Critique of European Policies and Proposals for Alternatives (Palgrave Macmillan), pp. 49-60.

Iglesias Sánchez, Sara (2014). "Unfair Terms in Mortgage Loans and Protection of Housing in Times of Economic Crisis: Aziz c. Catalunyacaixa", Common Market Law Review, Vol. 51, N 3, pp. 955-974.

Incardona, Rossella y Poncibó, Cristina (2007). "The Average Consumer, the Unfair Commercial Practices Directive, and the Cognitive Revolution", fournal of Consumer Policy, Vol. 30, pp. 21-38.

Instituto Nacional de Estadísticas (INE) (2014). "Foreclosure Statistics. Fourth quarter of 2014 and Year 2014. Provisional data", Press Release, en: www.ine. es/en/daco/daco42/eh/eh0414_en.pdf.

Jappeldi, Tullio y Pagano, Marco (2002). "Information sharing, lending and defaults: Cross-country evidence", fournal of Banking and Finance, Vol. 26, Issue 10, pp. 2017-2045.

Jolls, Christine; Sunstein, Cass R. y Thaler, Richard (1998). "A Behavioral Approach to Law and Economics", Stanford Law Review, Vol. 50, Issue 5, pp. 1471-1549.

Kemeny, Jim (2004). "Home ownership against the welfare state: The thesis and the evidence", ENHR Conference, Cambridge University 2-6 July 2004, pp. 1-10.

Kessler, Friedrich (1943). "Contracts of Adhesion-Some Thoughts about Freedom of Contract", Columbia Law Review, Vol. 43, N 5, pp. 629-642.

Koops, Bert-Jaap (2011). "The (in)flexibility of Techno-Regulation and the Case of Purpose-binding”, Legisprudence, Vol. 5, N², pp. 171-194.

KorczaK, Dieter (2009). "Der öffentliche Umgang mit privaten Schulden", Aus Politik und Zeitgeschichte, Vol. 26, pp. 26-32. 
Krippner, Greta R. (2005). "The financialization of the American economy", Socio-Economic Review, Vol. 3, Issue 2, pp. 173-208.

Lazzarrato, Maurizio (2015). Governing by Debt (MIT Press).

LeEse, Matthias (2014). "The new profiling: Algorithms, black boxes, and the failure of anti-discriminatory safeguards in the European Union", Security Dialogue, Vol. $45 \mathrm{~N}^{\circ}$ 5, pp. 494-511.

Levine, David K. (2009). "Is Behavioural Economics doomed? The Ordinary versus the Extraordinary", Max Weber Lecture Series, MWP-LS 2.

Logemann, Jan (ed.) (2012). The Development of Consumer Credit in Global Perspective (Palgrave Macmillan).

LONG, Gideon (2016). "Story of cities \#33: how Santiago tackled its housing crisis with 'Operation Chalk'”, The Guardian, 29 April 2016, in: https://www.theguardian.com/cities/2016/apr/29/story-cities-33-santiago-chile-housing-crisis-operacion-sitio-operation-chalk.

Mak, Vanessa (2013). “The 'Average Consumer' of EU Law in Domestic and European Litigation”, in Leczykiewicz D. \& Weatherill, S. (eds.), The Involvement of EU Law in Private Law Relationships (Hart Publishing), pp. 333-356.

Mattei, Ugo (2014). 'Senza proprietá non c'è libertá” (Falso!) (Idòla Laterza).

Mian, Atif y Sufi, Amir (2014). House of Debt - How They (and You) Caused the Great Recession, and How We Can Prevent It from Happening Again (University of Chicago Press).

Micco, Alejandro; Parrado, Eric; Piedrabuena, Bernardita y Rebucai, Alessandro (2012). "Housing Finance in Chile: Instruments, Actors, and Policies", IDB Working Paper Series, No IDB-WP-312.

Micklitz, Hans W. (2013). "Comment to Case C415/11, Mohamed Aziz V Caixa D'Estalvis de Catalunya, Tarragona I Manresa (Catalunyacaixa), NYR”, in Terryn, E.; Straetmans, G. \& Colaert, V. (eds.), Landmark Cases of EU Consumer Law - In Honour of Jules Stuyck (Intersentia), pp. 633-652.

Micklitz, Hans W. (2010). "The Paradox of Access in Financial Services for Consumers", European Journal of Consumer Law, Vol. 1, pp. 7-26.

Micklitz, Hans W. y Reich, Norbert (2014). "The Court and the Sleeping Beauty: the revival of the Unfair Contract Terms Directive (UCTD)", Common Market Law Review, Vol. 51, Issue 3, pp. 771-808.

Momberg Uribe, Rodrigo (2011). The effect of a change of circumstances on the binding force of contracts (Intersentia).

Olson, Mark W. (2003). "Increased Availability of Financial Products and the Need for Improved Financial Literacy", en: http://www.federalreserve.gov/boarddocs/speeches/2003/20030922/default.htm.

Paredes, Troy A. (2003). "Blinded by the Light: Information Overload and its Consequences for Securities Regulation", Washington University Law Quaterly, Vol. 81, Issue 2, pp. 417-485. 
Parker, David (1998). "Privatisation in the European Union: an Overview", en del mismo (ed.), Privatisation in the European Union - Theory and Policy Perspectives (Routledge), pp. 10-48.

Pierson, Paul (1996). "The New Politics of the Welfare State”, World Politics, Vol. 48, Issue 2, pp. 143-179.

Prieto Larraín, María Cristina (2011). Branding the Chilean Nation Socio-Cultural Change, National Identity and International Image (Diss. Department of Latin American Studies, Leiden Institute for History, Faculty of Humanities, Leiden University).

Ramsay, Iain (2017). Personal Insolvency in the 21st Century (Hart Publishing Ltd).

RamsaY, Iain (1995). "Consumer Credit Law, Distributive Justice and the Welfare State”, Oxford Fournal of Legal Studies, Vol. 15, º 2, pp. 177-197.

Richards, Ben (1995). "Poverty and Housing in Chile: the Development of a Neo-liberal Welfare State", Habitat International, Vol. 19, N 4, pp. 515-527.

Rona-Tas, Akos (2015). "The Role of Credit Bureaus in Globalised Economies: Why They Matter Less Than We Think and How They Can Matter More", en Micklitz, Hans W. y Domurath, Irina (eds.), Consumer Debt and Social Exclusion in Europe (Ashgate Publishing Ltd), pp. 177-188.

Rona-Tas, Akos y Hiss, Stefanie (2008). "Consumer and Corporate Credit Ratings and the Subprime Crisis in the U.S. with Some Lessons for Germany", Wiesbaden: SCHUFA.

Rose, Nikolas (1999). Powers of Freedom - Reframing Political Thought (Cambridge University Press).

Rotт, P. (2014). "Verbraucherschutz durch Prüfung der Kreditwürdigkeit Bedeutung des EuGH-Urteils vom 27.3.2014- Rs. C-561/12 LCL Le Crédit Lyonnais für das deutsche Recht", Europäische Zeitschrift für Wirtschafts- und Steuerrecht, Vol. 4, pp. 211-215.

Roтt, P. (2012). "Verbraucherschutz im Bereich Finanzdienstleistungen", in TonNER, Klaus y TAmm, Marina (eds.), Verbraucherrecht - Rechtliches Umfeld, Vertragstypen, Rechtsdurchsetzung (Nomos Verlagsgesellschaft), pp. 661-811.

Rott, P.; Terryn, E. \& Twigg-Flesner, C. (2011). "Kreditwürdigkeitsprüfung: Verbraucherschutzverhinderung durch Zuweisung zum Öffentlichen Recht?", Verbraucher und Recht, Vol. 26, Issue 5, pp. 163-167.

Rubim Borges Fortes, Pedro (2016). "The Future of Contract Law in Latin America”, European Review of Private Law, Vol. 24, Issue 2, pp. 287-296.

Scatigna, Michela \& Tovar, Camilo E. (2007). "Securitization in Latin America", BIS Quarterly Review, September 2007, pp. 71-82.

Schwartz, Herman (2012). "Housing, the Welfare State, and the Global Financial Crisis", Politics and Society, Vol. $40 \mathrm{~N}^{\circ}$ 1, pp. 35-38.

Sharot, Tali (2011). "The optimism bias", Current Biology, Vol. 21, Issue 23, pp. 941-945. 
Simián, José Miguel (2010). Logros y desafios de la política habitacional en Chile (Centro de Estudios Públicos).

Silva, Eduardo (1991). "The Political Economy of Chile's Regime Transition: From Radical to 'Pragmatic' Neo-liberal policies", en Drake, P.W. y Jaksic, I. (eds.), The Struggle for Democracy in Chile 1982-1990 (University of Nebraska Press), pp. 98-121.

SPINDLER, Gerald (2011). "Behavioural Finance and Investor Protection Regulations", Fournal of Consumer Policy, Vol. 34, Issue 3, pp. 315-336.

STARK, Jürgen (2009). "Monetary Policy before, during and after the financial crisis", en: https://www.ecb.europa.eu/press/key/date/2009/html/sp091 109.en.ht$\mathrm{ml}$

Trumbull, Gunnar (2012a). "Banking on Consumer Credit: Explaining Patterns of Household Borrowing in the United States and France", en Logemann, Jan (ed.), The Development of Consumer Credit in Global Perspective (Palgrave Macmillan), pp. 157-182.

Trumbull, Gunnar (2012b). "Credit Access and Social Welfare: The Rise of Consumer Lending in the United States and France”, Politics \& Society, Vol. 40, Issue 1, pp. 9-34.

VALdÉs, Juan Gabriel (2008). Pinochet's Economists: The Chicago School of Economics in Chile (Cambridge University Press).

Vandone, Daniela (2009). Consumer Credit in Europe - Risks and opportunities of a Dynamic Industry (Springer Verlag).

Whitford, William C. (1973). "The Functions of Disclosure Regulation in Consumer Transactions", Wisconsin Law Review, Vol. 2, pp. 400-470.

Wilhelmsson, Thomas (2004). "Varieties of Welfarism in European Contract Law", European Law Fournal, Vol. 10, Issue 6, pp. 712-733.

Wilhelmsson, Thomas (1993). "Control of unfair contract terms and social values: EC and Nordic approaches", fournal of Consumer Policy, Vol. 16, Issue 3-4, pp. 435-453.

Wilhelmsson, Thomas (1990). "Social Force Majeure - A New Concept in Nordic Consumer Law”, Fournal of Consumer Policy, Vol. 13, Issue 1, pp. 1-14. 


\section{JURISPRUDENCIA CITADA}

\section{Chile:}

Guillermo Larraín Vial con Servicio de Vivienda y Urbanización de la Región Metropolitana (2006). Corte de Apelaciones de Santiago, 14 de diciembre de 2006.

\section{Unión Europea:}

Árpád Kásler, Hajnalka Káslerné Rábai v OTP Jelzálogbank Zrt (2014). CJEU, Judgment of 30 April 2014, C-26/13, ECLI:EU:C:2014:282 (Kásler).

Cofidis SA v Jean-Luois Fredout (2002). CJEU, Judgment of 21 November 2002, C-473/00, ECLI:EU:C:2002:705.

Federal Republic of Germany v European Parliament and Council of the European Union (2000). CJEU, Judgment of 5 October 2000, G-376/98, ECLI:EU:C:2000:54.

Juan Carlos Sánchez Morcillo and María del Carmen Abril García v Banco Bilbao Vizcaya Argentaria SA (2014). GJEU, Judgment of 17 July 2014, G-169/14, ECLI:EU:C:2014:2099 (Sánchez Morcillo).

LCL Le Crédit Lyonnais SA v Fesih Kalhan (2014). CJEU, Judgment of 27 March 2014, C-565/12, ECLI:EU:C:2014:190.

Mohamed Aziz v Caixa d'Estalvis de Catalunya, Tarragona i Manresa (Catalunyacaixa) (2013). GJEU, Judgment of 14 March 2013, C-415/11, EGLI:EU:C:2013:164.

Nemzeti Fogyasztóvédelmi Hatóság v Invitel Távközesi Zrt (Invitel) (2012). CJEU, Judgment of 26 April 2012, G-472/10, ECLI:EU:G:2012:242.

Océano Grupo Editorial SA v Roció Murciano Quintero (C-240/98) and Salvat Editores SA v José M. Sánchez Alcón Prades (C-241/98), José Luis Copano Badillo (C-242/98), Mohammed Berroane (C-243/98) and Emilio Viñas Feliu (C-244/98) (2000). CJEU, Judgment of 27 June 2000, Joined Cases C-240/98 to 244/98.

Pannon GSM Zrt v Erz'ebet Sustikn'e Gy'orfi (2009). GJEU, Judgment of 3 June 2009, C-243/08, ECLI:EU:C:2009:350.

Rewe Zentral v Bundesmonopolverwaltung fir Branntwein (1979). CJEU, Judgment of 20 February 1979, G-120/78, ECLI:EU:C:1983:202 (Cassis de Dijon).

VB Pezügï Lizing Zrt v Ferenc Schneider (2010). CJEU, Judgment of 9 November 2010, C-137/08, ECLI:EU:C:2010:659.

Verein gegen Unwesen in Handel und Gewerbe Köln eV v Mars GmbH (1995). CJEU, Judgment of 6 July 1995, G-470/93, ECLI:EU:C:1995:224. 


\section{NORMAS GITADAS}

\section{Chile:}

Decreto con Fuerza de Ley N 3, de 26 de noviembre de 1997, Ley General de Bancos.

\section{España:}

Decreto-ley 7/2013 de 28 de junio de 2013, de medidas urgentes de naturaleza tributaria, presupuestarias y de fomento de la investigación, el desarrollo y la innovación. BOE No 155, of 29 June 2013, p. 48767, the 'LEG.'

Ley $1 / 2013$ de 14 de mayo de 2013, Ley de medidas para reforzar la protección a los deudores hipotecarios, reestructuración de deuda y alquiler social. BOE No 116, of 15 May 2013, p. 36373, 'Ley 1/2013'.

Ley de Enjuiciamiento Civil de 7 de enero de 2000. BOE No 7, de 8 de enero 2000, p. 575.

\section{Unión Europea:}

Council Directive 93/13/EEG of 5 April 1993 on unfair terms in consumer contracts, OJ L 95/29.

Council Regulation 24/2013 of 15 October 2013 conferring specific tasks on the European Central Bank concerning policies relating to the prudential supervision of credit institutions, OJ L 287/63.

Directive 2008/48/EG of the European Parliament and of the Council of 23 April 2008 on credit agreements for consumers and repealing Council Directive 87/102/EEG, OJ L 133/66.

Directive 2014/17/EU of the European Parliament and of the Council of 4 February 2014 on credit agreements for consumers relating to residential immovable property and amending Directives 2008/48/EC and 2013/36/EU and Regulation (EU) No 1093/2010, OJ L 60/34.

Treaty on the Functioning of the European Union of 1 December 2009, OJ L 83/47, 30.03.2010. 